Article

\title{
Investigate on a Simplified Multi-Port Interline DC Power Flow Controller and Its Control Strategy
}

\author{
Wen $W u^{1} \mathbb{D}$, Xuezhi $\mathrm{Wu}^{1,2, *}$, Long Jing ${ }^{1}$ and Jingyuan Yin ${ }^{3}$ \\ 1 National Active Distribution Network Technology Research Center, Beijing Jiaotong University, \\ Beijing 100044, China \\ 2 Collaborative Innovation Center of Electric Vehicles, Beijing 100044, China \\ 3 The Institute of Electrical Engineering Chinese Academy of Sciences, Beijing 100190, China \\ * Correspondence: xzhwu@bjtu.edu.cn; Tel.: +86-135-0129-1928
}

Received: 9 May 2019; Accepted: 26 June 2019; Published: 27 June 2019

\begin{abstract}
A DC power flow controller (DCPFC) can help to facilitate power flow routing in the multi-terminal high-voltage direct current (HVDC) transmission system. Realizing its multi-port output can effectively improve the device regulate range and capability. Based on analysis of the traditional multi-port interline DC power flow controller (MI-DCPFC), this paper presents a switches reduced topology of MI-DCPFC. In addition, for solving the problem of coupling of the port-output voltage of the traditional MI-DCPFC, a novel control strategy based on carrier phase shifting pulse width modulation (CPS-PWM) is proposed. It implements the decoupling of the port-output voltage of MI-DCPFC, which can ensure completely independent tracking of the power flow regulating commands for different controlled lines. Moreover, key relationships between the system state variables are also analyzed and detailed in this study. Finally, the performance of the proposed controller and control strategy are confirmed with the simulation and experiment studies under different conditions.
\end{abstract}

Keywords: multi-terminal HVDC transmission system; DC power flow control; multi-port topology; decoupling; control strategy

PACS: J0101

\section{Introduction}

Realizing the development and utilization of green and clean energy has become a major trend to solve problems such as traditional energy shortages and environmental degradation. To ensure the consumption and efficient use of the large scale new energy, effective transmission technology is needed as a support [1]. As the multi-terminal high-voltage direct current (HVDC) transmission system has the advantages of long transmission distance capability, large capacity and a flexible operation mode, etc., it has therefore become one of the main means to facilitate grid connections of large-scale renewable energy [2].

Unreasonable distribution of the transmission line currents can introduce unnecessary transmission line losses, or even an overload of the converter station. In order to facilitate the power flow management inside the DC transmission network, inspired by the idea of power flow control devices developed in the AC transmission system, such as a unified power-flow controller (UPFC) and thyristor controlled series compensator (TCSC), a DC power flow controller (DCPFC) can be introduced in the multi-terminal HVDC transmission system [3]. However, since the DC system does not have reactive power, reactance and phase angle, its power flow control can only be realized by adjusting the resistance or DC voltage 
of the transmission line. Therefore, there are two general design approaches for the DCPFC, which are a resistance control type and a DC voltage control type.

(1) For the resistance control type DCPFC, different implementation schemes have been designed in reference [4] and reference [5]. This kind of control scheme is simple to implement, but it can only adjust the equivalent resistance of the line in one direction, which limits its power flow control ability.

(2) For the DC voltage control type DCPFC, according to the voltage regulation means, it can be further divided into three main types, which are (1) a DC transformer type [6-10], (2) an auxiliary voltage source type [11-15] and (3) a capacitor-based interline energy-exchanged type [3,16-24]. In comparison, the DCPFC of capacitor-based interline energy-exchanged type has more advantages and better application prospects. For instance, it has fewer power devices; does not require an external power supply device; and can avoid withstanding the system-level high voltage and power, which help reduce the stress requirements of the power devices and system losses. Therefore, it has become a kind of DCPFC which is currently more researched and heavily focused on $[3,20]$.

The capacitor-based interline energy-exchanged type DCPFC is usually called the interline DCPFC (IDCPFC). As shown in Figure 1, its main control idea is to exchange the power between different transmission lines by charging/discharging the capacitor of IDCPFC, thereby achieving the power flow control of the transmission lines. Based on the concept depicted in Figure 1a, two current flow controller (CFC) topologies were first proposed in reference [16], however, only the basic conceptualization is introduced, its working principles and control method are not investigated enough. Focus on one topology of the CFC, its control strategy and operation principles were discussed in reference [17]. Focus on the control method of another method was designed in references $[18,19]$. In addition, its operation states were analyzed, and an average mode which can be used for perform steady-state analysis was derived in reference [19]. Furthermore, in order to simplify the CFC circuit structure, an improved CFC topology was proposed in reference [20], and its characteristics were detailed compared to the traditional CFC topology proposed in reference [16]. Based on the concept depicted in Figure $1 \mathrm{~b}$, by increasing the DC capacitor number and introducing coupled inductors, a novel type of IDCPFCs with independent connections of the capacitor in two lines were respectively investigated in references [3,21-23]. In reference [24], the application modular multilevel converter (MMC) device was also considered, and an MMC-based IDCPFC was proposed. These schemes in reference [3,21-24] avoided the capacitor switching in the line. However, it should be noted that all the above existing topologies are characterized by two-port characteristics, which can only assist in regulating the current on one line. If the power flow control of multiple lines is required at the same time, the corresponding multi-port topology should be developed, and this problem is also an area that this paper deals with.

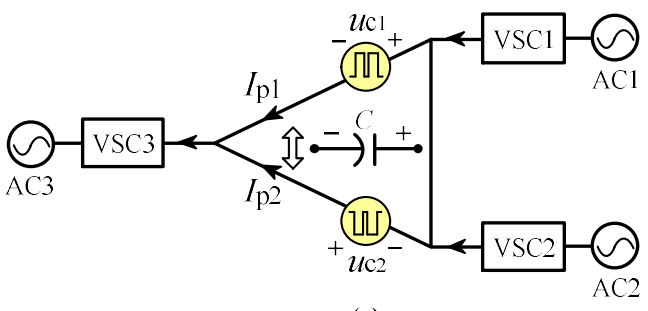

(a)

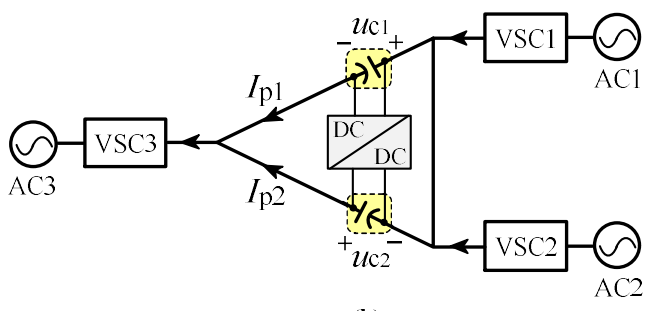

(b)

Figure 1. Schematic diagrams of the IDCPFC control principle: (a) The single-capacitor control type in references [16-20]; (b) The dual-capacitor control type in references [3,21-24].

Currently, the research on multi-port IDCPFC (MI-DCPFC) is still in its infancy. Based on the MMC-based IDCPFC proposed in reference [24], a MI-DCPFC topology based on MMC was developed in reference [25]. However, it requires multi-winding transformers and needs to connect MMC in each 
control line, which leads to higher system costs. In addition, with the controlled line number being increased, its circuit topology and control system become relatively complicated. In reference [26], a MI-DCPFC topology based on identical insulated gate bipolar transistor (IGBT) half-bridge was proposed. Its system structure is simple, and the cost of the port expansion is low. However, as only a basic control method is introduced, it can not achieve independent tracking of the current regulation commands for each transmission line, where the power flow regulating has limited freedom.

Combining the precious work in reference [26], this paper presents a switches reduced topology of MI-DCPFC. In addition, for solving the problem of coupling of the port-output voltage of the traditional MI-DCPFC, a novel control strategy based on carrier phase shifting pulse width modulation (CPS-PWM) is proposed. This strategy achieved the decoupling of the port-output voltage, which can ensure independent tracking of the power flow regulating commands for different controlled lines. Moreover, key relationships between the system state variables were also detailed in this study. Finally, two five-terminal HVDC transmission systems were developed, and the performance of the proposed controller and control strategy were confirmed with the simulation and experiment studies under different conditions. The remainder of this paper is organized as follows: the traditional MI-DCPFC including its topology and control strategy is analyzed in Section 2. The topology and operation principles of the simplified MI-DCPFC are analyzed in Section 3. The novel control strategy is designed and the relationships between the system state variables are discussed in Section 4. The simulation and experiment verifications are respectively carried out in Section 5 and 6. Finally, a conclusion is given in Section 7.

\section{Analysis of the Traditional MI-DCPFC}

\subsection{Multi-Terminal HVDC Transismion System}

The following work actually can be applied to any high voltage direct current (HVDC) transmission system. For this study, in order to facilitate the verification of the three- and four-port multi-port interline DC power flow controller (MI-DCPFC) in the subsequent simulations and experiments, a monopole five-terminal HVDC transmission system, as shown in Figure 2, was adopted as an example to carry out the related analysis. The voltage source converter (VSC) 4 is set as the DC voltage regulator node, which operates in the constant DC voltage control mode; The VSC1-3 and VSC5 are set as power regulator nodes, which operate in the constant power control mode.

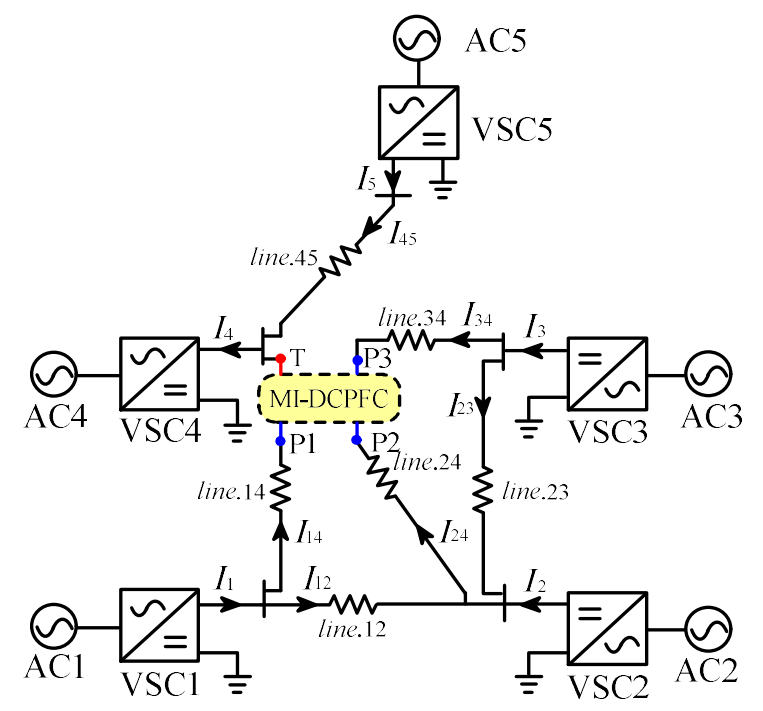

Figure 2. Diagram of the five-terminal HVDC transmission system with a three-port MI-DCPFC. 


\subsection{Traditional Topology}

The schematic diagram of traditional MI-DCPFC is shown in Figure 3. For a three-port topology, it consists of six IGBT half-bridges (HBs) and a common capacitor C. $\mathrm{S}_{\mathrm{a} i}(I=1,2,3)$ and $\mathrm{S}_{\mathrm{b} i}$ are the upper and lower switches of $\mathrm{HB}_{0}, \mathrm{HB}_{1}, \mathrm{HB}_{2}$, respectively. $\mathrm{S}_{\mathrm{c} i}$ and $\mathrm{S}_{\mathrm{d} i}$ are the upper and lower switches of $\mathrm{HB}_{3}, \mathrm{HB}_{4}, \mathrm{HB}_{5}$, respectively. In addition, as depicted in Figure 2, when the MI-DCPFC is accessed in the transmission system, its terminal $T$ is connected to the bus convergence point of the different power regulator nodes, that is, the DC bus side of VSC4. Meanwhile, its terminals $P_{i}$ are respectively connected to the different transmission lines, that is, the DC bus side of VSC1 to 3.

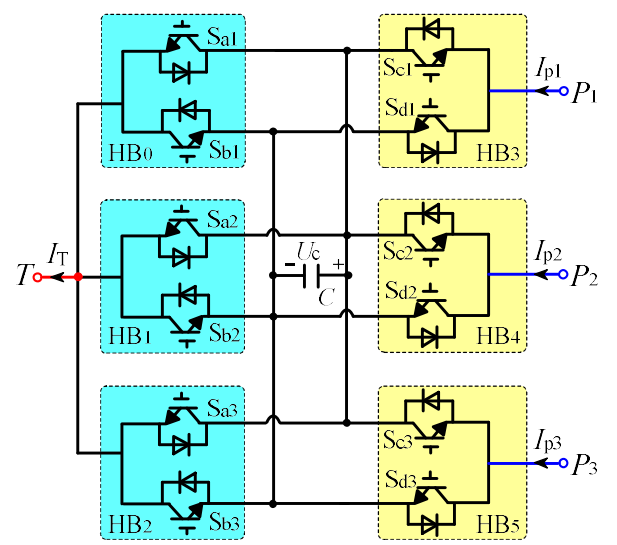

Figure 3. Topology of the traditional three-port MI-DCPFC [26].

\subsection{Traditional Control Method}

According to different line current directions and different control targets, there are total 12 working modes of the traditional three-port MI-DCPFC, which are shown in Table 1. Under the traditional control method, the switches $\mathrm{S}_{\mathrm{a} i}(i=1,2,3)$ and $\mathrm{S}_{\mathrm{b} i}$ are pulsed by the obtained PWM signals under the forward and reverse direction, respectively. On this basis, all other swtiches remain in the on or off state, where the specific conduction states of the switches $\mathrm{S}_{\mathrm{c} i}$ and $\mathrm{S}_{\mathrm{d} i}$ are shown in the Table A1 in the Appendix A. Take the working-modes 1 and 6 as examples to provide further analysis, respectively.

Table 1. Working-modes of the traditional three-port MI-DCPFC.

\begin{tabular}{|c|c|c|c|c|c|c|c|c|c|}
\hline \multirow{2}{*}{ Mode } & \multirow{2}{*}{ Direction } & \multirow{2}{*}{ Reduced } & \multirow{2}{*}{ Increased } & \multicolumn{6}{|c|}{ Switching States } \\
\hline & & & & $\mathrm{S}_{\mathrm{a} 1}$ & $S_{\mathrm{a} 2}$ & $\mathrm{~S}_{\mathrm{a} 3}$ & $S_{b 1}$ & $S_{b 2}$ & $S_{b 3}$ \\
\hline 1 & forward & $I_{\mathrm{p} 1}$ & $I_{\mathrm{p} 2}$ and $I_{\mathrm{p} 3}$ & & & & & & \\
\hline 2 & forward & $I_{\mathrm{p} 2}$ & $I_{\mathfrak{p} 1}$ and $I_{\mathfrak{p} 3}$ & & & & & & \\
\hline 3 & forward & $I_{\mathrm{p} 3}$ & $I_{\mathrm{p} 1}$ and $I_{\mathrm{p} 2}$ & & & & & off & \\
\hline 4 & forward & $I_{\mathrm{p} 1}$ and $I_{\mathrm{p} 2}$ & $I_{\mathrm{p} 3}$ & & & & & & \\
\hline 5 & forward & $I_{\mathrm{p} 1}$ and $I_{\mathrm{p} 3}$ & $I_{\mathrm{p} 2}$ & & & & & & \\
\hline 6 & forward & $I_{\mathrm{p} 2}$ and $I_{\mathrm{p} 3}$ & $I_{\mathrm{p} 1}$ & & & & & & \\
\hline 7 & reverse & $I_{\mathrm{p} 1}$ & $I_{\mathrm{p} 2}$ and $I_{\mathrm{p} 3}$ & & & & & & \\
\hline 8 & reverse & $I_{\mathrm{p} 2}$ & $I_{\mathrm{p} 1}$ and $I_{\mathrm{p} 3}$ & & & & Con & & \\
\hline 9 & reverse & $I_{\mathrm{p} 3}$ & $I_{\mathrm{p} 1}$ and $I_{\mathrm{p} 2}$ & & off & & & & \\
\hline 10 & reverse & $I_{\mathrm{p} 1}$ and $I_{\mathrm{p} 2}$ & $I_{\mathrm{p} 3}$ & & off & & & & \\
\hline 11 & reverse & $I_{\mathrm{p} 1}$ and $I_{\mathrm{p} 3}$ & $I_{\mathrm{p} 2}$ & & & & & & \\
\hline 12 & reverse & $I_{\mathrm{p} 2}$ and $I_{\mathrm{p} 3}$ & $I_{\mathrm{p} 1}$ & & & & & & \\
\hline
\end{tabular}

Figure 4 shows the conduction diagrams of the traditional MI-DCPFC under working-mode 1. The shunt branches connected to the terminals $P_{1}, P_{2}$ and $P_{3}$ are respectively named line 1 , line 2 and line 3. According to the conduction states of the switches $S_{a}$, the working process can be divided into the following two stages: 
(i) Stage 1: switches $S_{a i}$ are truned-off. During this period, as shown in Figure 4a, the current $I_{\mathrm{p} 1}$ is charging the capacitor through the feedback diodes of $S_{\mathrm{b} 1}$ and $S_{\mathrm{c} 1}$, while the currents $I_{\mathrm{p} 2}$ and $I_{\mathrm{p} 3}$ are flowing out directly through the $S_{\mathrm{d} 2}$, feedback diode of $S_{\mathrm{b} 2}$ and $S_{\mathrm{d} 3}$, feedback diode of $\mathrm{S}_{\mathrm{b} 3}$, respectively.

(ii) Stage 2: switches $S_{a i}$ are truned-on. During this period, as shown in Figure $4 \mathrm{~b}$, the current $I_{\mathrm{p} 1}$ is flowing out directly through the $S_{\mathrm{a} 1}$ and feedback diode of $S_{\mathrm{c} 1}$, while the currents $I_{\mathrm{p} 2}$ and $I_{\mathrm{p} 3}$ are discharging the capacitor through $\mathrm{S}_{\mathrm{a} 2}, \mathrm{~S}_{\mathrm{d} 2}$ and $\mathrm{S}_{\mathrm{a} 3}, \mathrm{~S}_{\mathrm{d} 3}$ respectively. The charging and discharging states are kept interchanging to transfer the power from line 1 to lines 2 and 3 . As a result, the the current $I_{\mathrm{p} 1}$ is reduced, $I_{\mathrm{p} 2}$ and $I_{\mathrm{p} 3}$ are increased.

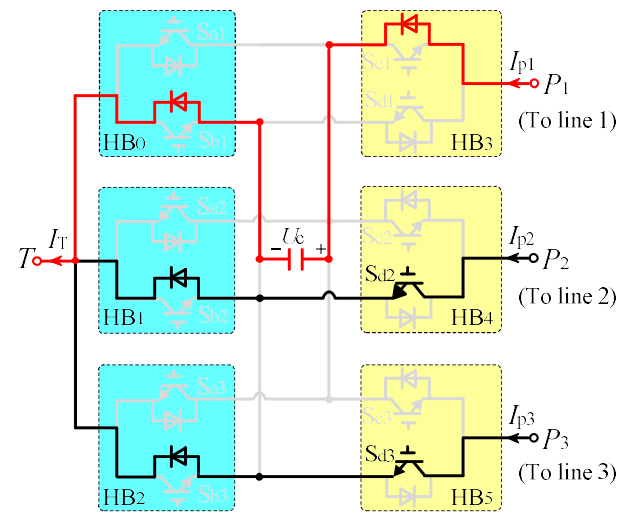

(a)

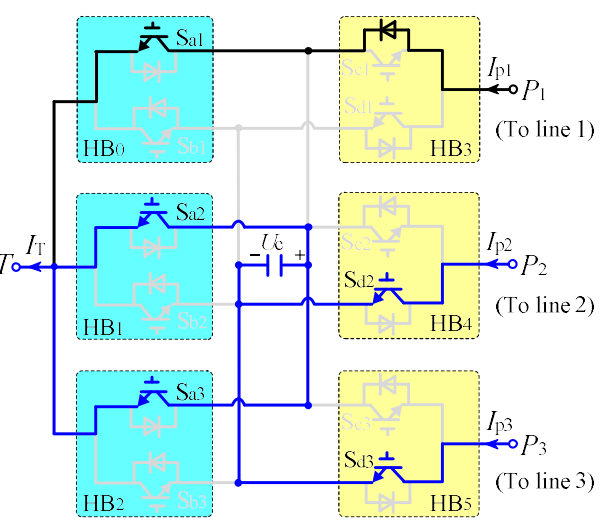

(b)

Figure 4. Conduction diagrams of the traditional MI-DCPFC under working-mode 1: (a) conduction diagram during stage 1 ; (b) conduction diagram during stage 2.

Figure 5 shows the conduction diagrams of the traditional MI-DCPFC under working-mode 6. According to the conduction states of the switches $S_{a i}$, the working process can also be divided into two stages. (i) Stage 1: switches $S_{a i}$ are truned-off. During this period, as shown in Figure 5a, the current $I_{\mathrm{p} 2}$ and $I_{\mathrm{p} 3}$ is charging the capacitor, while the current $I_{\mathrm{p} 1}$ is flowing out directly. (ii) Stage 2: switches $S_{\mathrm{a} i}$ are turned-on. During this period, as shown in Figure $5 \mathrm{~b}$, the current $I_{\mathrm{p} 2}$ and $I_{\mathrm{p} 3}$ was flowing out directly, while the currents $I_{\mathrm{p} 1}$ was discharging the capacitor to transfer the power from lines 2 and 3 to line 1 . As a result, the current $I_{\mathrm{p} 1}$ was increased, while $I_{\mathrm{p} 2}$ and $I_{\mathrm{p} 3}$ were reduced.

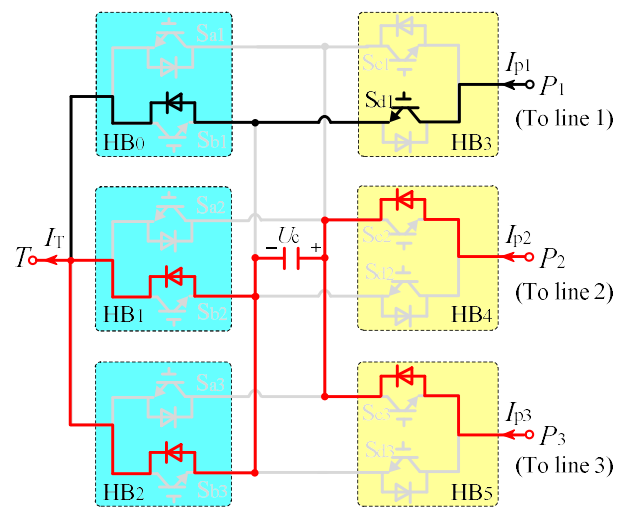

(a)

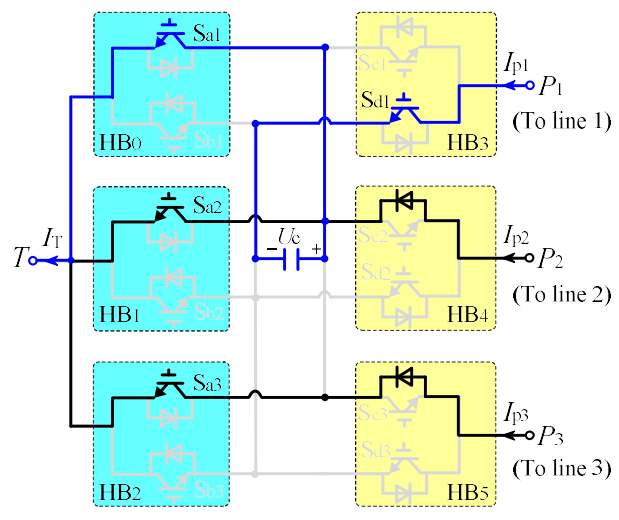

(b)

Figure 5. Conduction diagrams of the traditional MI-DCPFC under working-mode 6: (a) Conduction diagram during stage 1 ; (b) conduction diagram during stage 2.

\subsection{Summarizing of the Traditional Topology and Control Strategy}

Concluding the analysis in the previous section, we found that: 
(1) When completing the conduction states selection for the switches $\mathrm{S}_{\mathrm{c} i}$ and $\mathrm{S}_{\mathrm{d} i}$ in combination with Table A1, MI-DCPFC can achieve the power flow control by only pulsing the switches $\mathrm{S}_{\mathrm{a} i}$ or $\mathrm{S}_{\mathrm{b} i}$ under different working-modes. In addition, we can further observe that the switches $\mathrm{S}_{\mathrm{a} i}$ and $\mathrm{S}_{\mathrm{b} i}$ are always pulsed synchronously in the forward and reverse direction, respectively. Therefore, the switches $\mathrm{S}_{\mathrm{a} i}$ and $\mathrm{S}_{\mathrm{b} i}$ actually can be simplified as the upper switch and lower switch in one half-bridge, respectively.

(2) In the working-mode 1, the reduction control of $I_{\mathrm{p} 1}$ can be realized by pulsing the switches $\mathrm{S}_{\mathrm{a} i}$ with the obtained PWM signal. However, the lines 2 and 3 are always synchronized to discharge the capacitor, so the equivalent reverse polarity voltages introduced to the lines 2 and 3 are equal, which indicates that the specific increased amounts of the currents $I_{\mathrm{p} 2}$ and $I_{\mathrm{p} 3}$ cannot be controlled separately under the tradition control.

(3) In the working-mode 6, the reduction control of $I_{\mathrm{p} 2}$ and $I_{\mathrm{p} 3}$ can be simultaneously realized by also pulsing the switches $S_{a i}$. However, the lines 2 and 3 are always synchronized to charge the capacitor, so the equivalent forward polarity voltages introduced to the lines 2 and 3 are equal, which indicates that the specific reduced amounts of the currents $I_{\mathrm{p} 2}$ and $I_{\mathrm{p} 3}$ cannot be controlled separately under the tradition control.

(4) Generalizing the conclusions (ii) and (iii), it shows that among all the lines connected to MI-DCPFC, if there are multiple line currents that will be increased, an improved control strategy needs to be proposed to ensure that their respective increased values can be controlled independently. Similarly, if there are multiple line currents that will be reduced, the improved control strategy also needs to guarantee their respective reduced values can be independently controlled.

\section{Topology and Operation Principles of the Simplified MI-DCPFC}

\subsection{Topology}

According to the analysis in conclusions (1) in Section 2.4, a simplified MI-DCPFC topology is presented in this study. Its specific circuit diagram is shown in Figure 6. For an $n$-port MI-DCPFC, it consists of $n+1$ identical IGBT half-bridges and a DC capacitor $C$. $S_{a}$ and $S_{b}$ are the upper and lower switches of $\mathrm{HB}_{0}$, respectively. $\mathrm{T}_{i \mathrm{a}}$ and $\mathrm{T}_{i \mathrm{~b}}(i=1,2 \ldots n)$ are the upper and lower switches of $\mathrm{HB}_{i}$, respectively. Terminal $T$ is taken from $\mathrm{HB}_{0}$, and terminals $P_{i}$ are taken out from $\mathrm{HB}_{1}$ to $\mathrm{HB}_{n}$, respectively, the terminal $T$ and $P_{i}$ respectively compose $n$ different output ports $T P_{i}$ of the MI-DCPFC. $I_{\mathrm{P} i}$ are the DC currents flowing into MI-DCPFC through the different transmission lines; $I_{\mathrm{T}}$ is the DC current flowing out of MI-DCPFC.

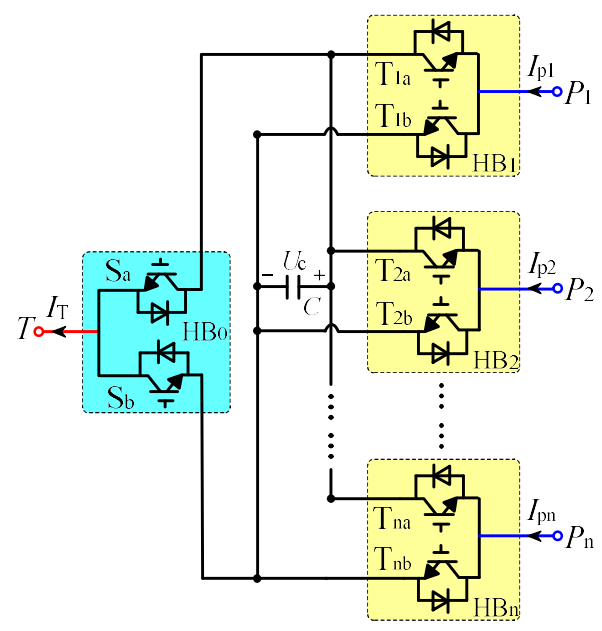

Figure 6. Topology of the simplified MI-DCPFC. 
When the simplified MI-DCPFC is connected to a multi-terminal HVDC transmission system, the diagram can also be depicted as Figure 2. It should be noted that the adopted five-terminal HVDC transmission system is unipolar, so it is only necessary to consider adding the DCPFC to the positive pole or negative pole of the system. However, for the bipolar system, in order to ensure the symmetry of the system, DCPFC needs to be simultaneously added to the positive and negative pole of the system.

In addition, compared with the traditional MI-DCPFC, in order to achieve independent control of the current of all controlled lines, the new working principle of the simplified MI-DCPFC needs to be considered, which is detailed in the next section.

\subsection{Operation Principles}

For easy analysis, a three-port simplified MI-DCPFC was adopted as an example, and the shunt branches connected to the terminals $P_{1}, P_{2}$ and $P_{3}$ were also respectively named line 1, line 2 and line 3. Similar to the traditional MI-DCPFC, the three-port simplified MI-DCPFC has the same 12 working-modes, as shown in Table 1 . In order to facilitate comparison with the traditional MI-DCPFC, we also chose working modes 1 (where control $I_{\mathrm{p} 1}$ reduced; $I_{\mathrm{p} 2}$ and $I_{\mathrm{p} 3}$ increased) and 6 (where control $I_{\mathrm{p} 1}$ increased; $I_{\mathrm{p} 2}$ and $I_{\mathrm{p} 3}$ reduced) to carry out detailed analysis.

\subsubsection{Working-Mode 1}

In this working-mode, according to the different conduction states of the switches in each half bridge, the working process of the MI-DCPFC can be divided into the following four stages. The conduction diagrams of the MI-DCPFC under this working-mode are depicted in Figure 7.

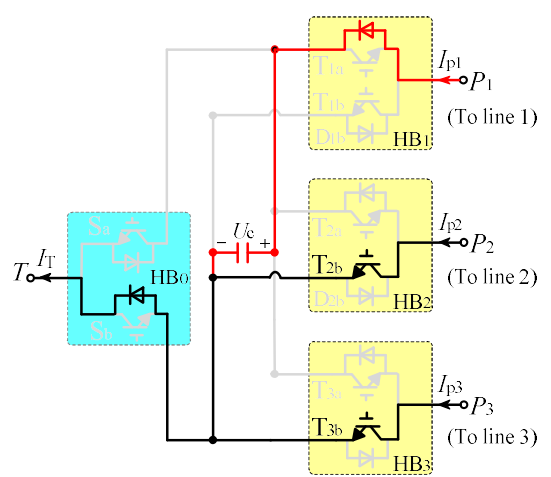

(a)

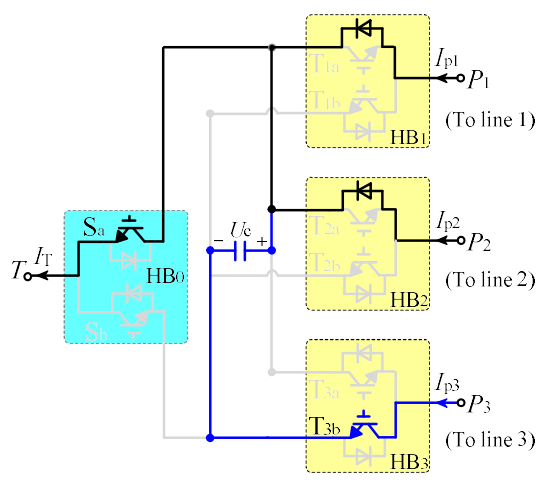

(c)

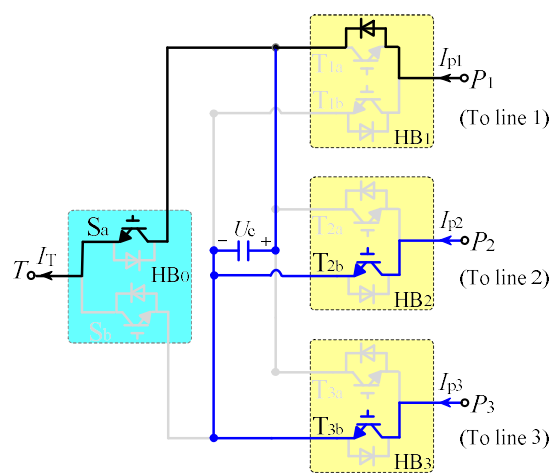

(b)

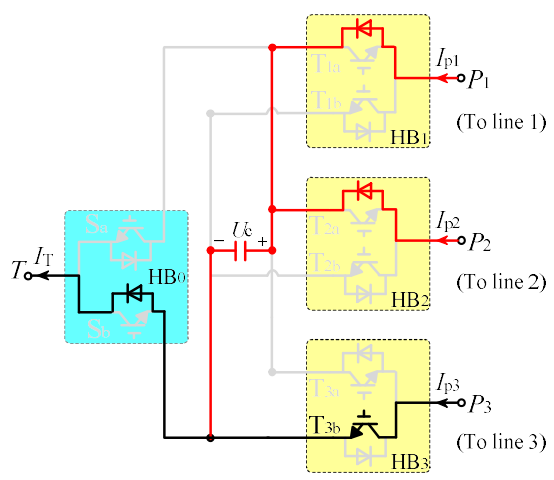

(d)

Figure 7. Conduction diagrams of the simplified MI-DCPFC under working-mode 1: (a) conduction diagram during stage 1 ; (b) conduction diagram during stage 2; (c) conduction diagram during stage 3; (d) conduction diagram during stage 4 . 
(i) Stage 1: turn on $\mathrm{T}_{2 \mathrm{~b}}$ and $\mathrm{T}_{3 \mathrm{~b}}$. During this period, as shown in Figure $7 \mathrm{a}$, the current $I_{\mathrm{p} 1}$ is charging the capacitor through the feedback diodes of $\mathrm{T}_{1 \mathrm{a}}$ and $\mathrm{S}_{\mathrm{b}}$, while the currents $I_{\mathrm{p} 2}$ and $I_{\mathrm{p} 3}$ are flowing out of the terminal $T$ directly.

(ii) Stage 2: keep $\mathrm{T}_{2 b}$ and $\mathrm{T}_{3 \mathrm{~b}}$ turned-on and turn on $\mathrm{S}_{\mathrm{a}}$. During this period, as shown in Figure $7 \mathrm{~b}$, the current $I_{\mathrm{p} 1}$ is flowing out of the terminal $T$ directly, while the currents $I_{\mathrm{p} 2}$ and $I_{\mathrm{p} 3}$ are discharging the capacitor through $\mathrm{T}_{2 b}, \mathrm{~S}_{\mathrm{a}}$ and $\mathrm{T}_{3 \mathrm{~b}}, \mathrm{~S}_{\mathrm{a}}$ respectively.

(iii) Stage 3: only keep $T_{3 b}$ and $S_{a}$ turned-on. During this period, as shown in Figure $7 c$, the currents $I_{\mathrm{p} 1}$ and $I_{\mathrm{p} 2}$ are directly flowing out of the terminal $T$, while the current $I_{\mathrm{p} 3}$ continues to discharge the capacitor through $T_{3 b}$ and $S_{a}$.

(iv) Stage 4: only keep $\mathrm{T}_{3 \mathrm{~b}}$ turned-on. During this period, as shown in Figure $7 \mathrm{~d}$, the currents $I_{\mathrm{p} 1}$ and $I_{\mathrm{p} 2}$ are charging the capacitor through the feedback diode of $\mathrm{T}_{1 \mathrm{a}}, \mathrm{S}_{\mathrm{b}}$ and feedback diode of $\mathrm{T}_{2 \mathrm{a}}, \mathrm{S}_{\mathrm{b}}$ respectively, while the current $I_{\mathrm{p} 3}$ is flowing out of the terminal $T$ directly.

With charging and discharging by the line currents, we assumed that the capacitor voltage of MI-DCPFC is balanced at $U_{\mathrm{c}}$. Concluding the analysis of the above, we can obtain the DC voltage introduced to the transmission line through the MI-DCPFC at various stages, as shown in Table 2.

Table 2. The DC voltage introduced to each line under working-mode 1.

\begin{tabular}{ccccc}
\hline Line & Stage $\mathbf{1}$ & Stage 2 & Stage 3 & Stage 4 \\
\hline 1 & $U_{\mathrm{c}}$ & 0 & 0 & $U_{\mathrm{c}}$ \\
2 & 0 & $-U_{\mathrm{c}}$ & 0 & $U_{\mathrm{c}}$ \\
3 & 0 & $-U_{\mathrm{c}}$ & $-U_{\mathrm{c}}$ & 0 \\
\hline
\end{tabular}

It can be observed that compared to the traditional MI-DCPFC, the stages 3 and 4 are added by auxiliary pulsing the lower switch of $\mathrm{HB}_{2}$. Based on this, the equivalent reverse polarity voltage introduced to the line 2 can be independently regulated, which indicates that the specific increased amounts of the currents $I_{\mathrm{p} 2}$ and $I_{\mathrm{p} 3}$ can be controlled individually at this time.

\subsubsection{Working-Mode 6}

In this working-mode, according to the different conduction states of the switches in each half bridge, the working process of the MI-DCPFC can also be divided into the following four stages. (i) Stage 1: only turn on $T_{1 b}$; (ii) Stage 2: keep $T_{1 b}$ turned-on and turn on $T_{3 b}$; (iii) Stage 3: keep $T_{1 b}$ and $\mathrm{T}_{3 \mathrm{~b}}$ turned-on and turn on $\mathrm{S}_{\mathrm{a}}$; (iv) Stage 4: only keep $\mathrm{T}_{1 \mathrm{~b}}$ and $\mathrm{S}_{\mathrm{a}}$ turned-on. The conduction diagrams during stages 1 to 4 are shown in Figure 8a-d, respectively.

Referring the previous analysis method, we can obtain the DC voltage introduced into the transmission line at various stages under this working-mode, which are shown in Table 3. It can be found that with auxiliary controlling the lower switch of $\mathrm{HB}_{3}$ in the simplified MI-DCPFC, the stages 2 and 3 are added to the operating process compared to the traditional MI-DCPFC. Based on this, the equivalent forward polarity voltages introduced to the lines 2 and 3 can be independently regulated, which indicates that the specific reduced amounts of the currents $I_{\mathrm{p} 2}$ and $I_{\mathrm{p} 3}$ can be controlled separately. In addition, according to the symmetry, when auxiliary pulsing the $\mathrm{HB}_{2}$ lower transistor, we can also achieve the control of the $I_{\mathrm{p} 1}$ that was increased and the $I_{\mathrm{p} 2}$ and $I_{\mathrm{p} 3}$ that were reduced.

Table 3. The DC voltage introduced to each line under working-mode 6.

\begin{tabular}{ccccc}
\hline Line & Stage 1 & Stage 2 & Stage 3 & Stage 4 \\
\hline 1 & 0 & 0 & $-U_{\mathrm{c}}$ & $-U_{\mathrm{c}}$ \\
2 & $U_{\mathrm{c}}$ & $U_{\mathrm{c}}$ & 0 & 0 \\
3 & $U_{\mathrm{c}}$ & 0 & $-U_{\mathrm{c}}$ & 0 \\
\hline
\end{tabular}




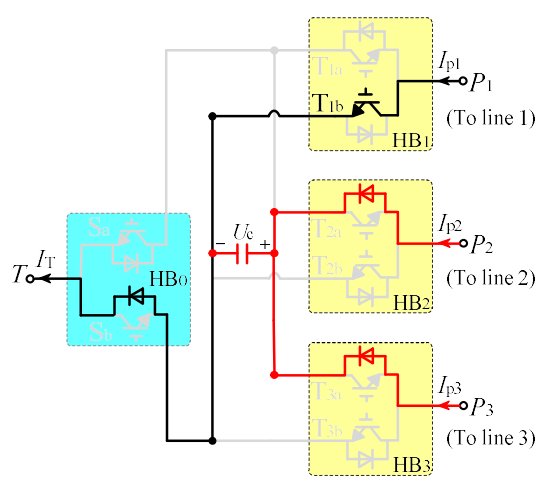

(a)

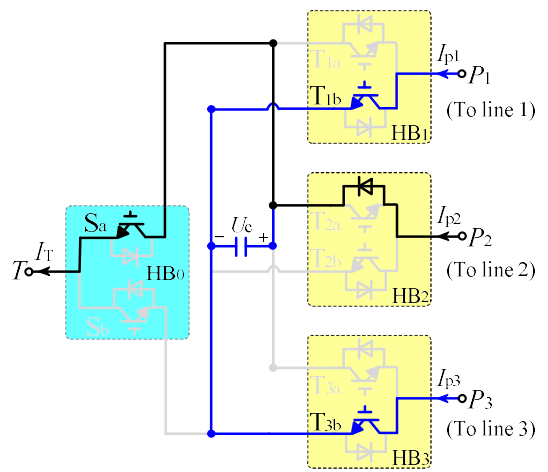

(c)

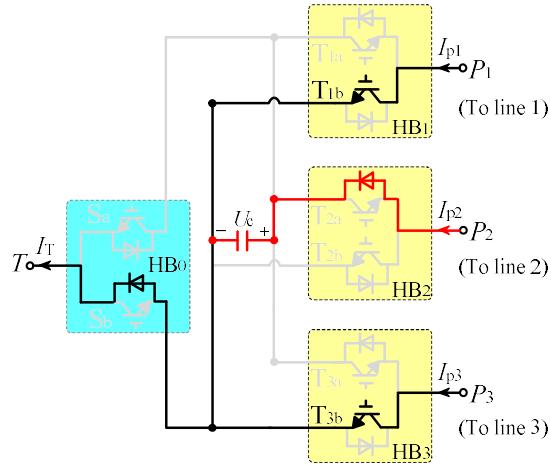

(b)

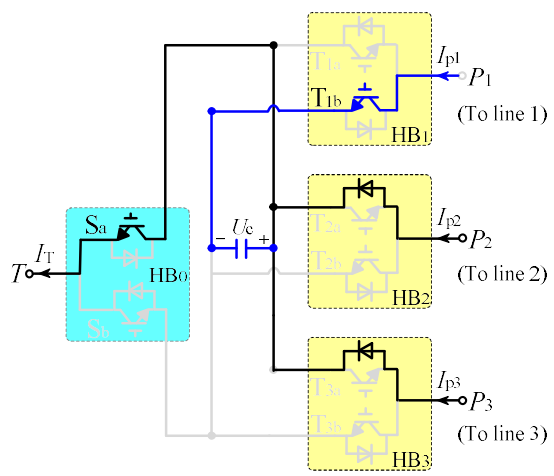

(d)

Figure 8. Conduction diagrams of the MI-DCPFC under working-mode 6: (a) conduction diagram during stage 1 ; (b) conduction diagram during stage 2; (c) conduction diagram during stage 3; (d) conduction diagram during stage 4 .

\subsubsection{Other Working-Modes}

As shown in Table 1, there are four other working-modes including 2, 3, 4 and 5 besides the above two analyzed working-modes. Similarly, when the current direction is reversed, six other working-modes are also derived. However, their working principles are similar to the analyzed working-modes 1 and 6 . The corresponding switching state of each transistor under different working-modes can be analyzed in a similar way. However, it is worth noting that since this type of MI-DCPFC cannot realize the reverse control of line current, when it is actually applied to a multi-terminal HVDC transmission system, it is relatively more suitable for the "multi-to-one" (such as multiple green and new energy are aggregated) or "one-to-many" (such as powering multiple zones) type of interconnected transmission structure.

Furthermore, when the MI-DCPFC is extended to the other ports number, its main working principle is similar to that of the three-port MI-DCPFC, which is reasonable to use to charge/discharge the capacitor on the different transmission lines. We will summarize the general control method of an arbitrary port MI-DCPFC in Section 4.3.

\section{Novel Control Strategy and Relationship Analysis of the System State Variables}

\subsection{CPS-PWM Control Strategy}

As analyzed in the Section 2.4, in order to achieve simultaneous tracking of the different current regulation commands for multiple transmission lines, the normal operation of MI-DCPFC needs to meet two regulation requirements: (i) When multiple line currents are increased, achieve independent amplification control of each line current (control-mode 1); (ii) When multiple line currents are reduced, achieve independent reduction control of each line current (control-mode 2). 
To solve this problem, a control strategy that is easier to implement based on the CPS-PWM control was designed. Firstly, we describe the specific implementation of the two control-modes detailed in combination with the three-port MI-DCPFC.

\subsubsection{Control-Mode 1}

Combined with the previous analysis in Section 3.2.1, it can be seen that when MI-DCPFC is operating in working-mode 1 , it is necessary to coordinate the amplification control of $I_{\mathrm{p} 2}$ and $I_{\mathrm{p} 3}$ by using the control-mode 1. Taking tracking the power flow regulating command of $I_{\mathrm{p} 2}$ as an example, the control block diagram is shown in Figure $9 . I_{\mathrm{p} 1}{ }^{*}$ is the regulation command of the current of line 1 . It subtracts the sampling current $I_{\mathrm{p} 1}$, where the error is sent to a PI regulator. Its output is compared with the triangular carrier, thereby obtaining the driving pulse of transistor $S_{a}$. Meanwhile, the next step involves tracking the error between the regulation command $I_{\mathrm{p} 2}{ }^{*}$ and sample current $I_{\mathrm{p} 2}$ of line 2 with a PI regulator, and then scaling it by the coefficient $k_{1}\left(k_{1}=-T_{\mathrm{S}} / 2\right.$, where $T_{\mathrm{s}}$ is the carrier period) to obtain the phase-shifted value of the original carrier. Finally, when comparing the phase-shifted carrier with the duty $D$ of pulse signal of $S_{a}$, the driving pulse of transistor $T_{2 b}$ can be obtained by NXORing the result with the pulse signal of $S_{a}$.

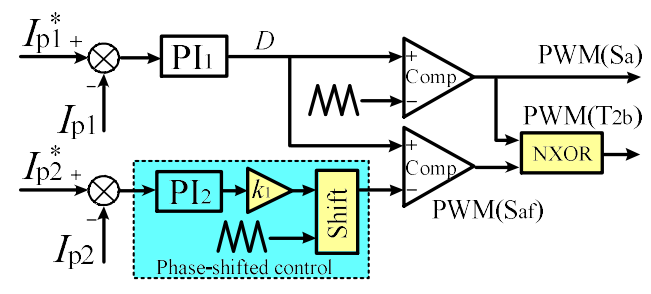

Figure 9. Block diagram of the control-mode 1 of the MI-DCPFC.

\subsubsection{Control-Mode 2}

When the MI-DCPFC is operating in working-mode 6, it needs to achieve the reduction control of $I_{\mathrm{P} 3}$ synchronized with the $I_{\mathrm{P} 2}$ reduction control by the control-mode 2 . The control block diagram is shown in Figure 10.

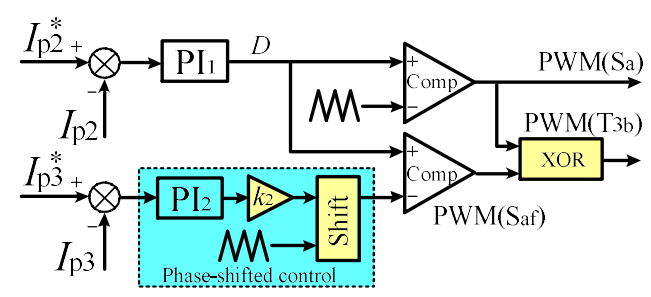

Figure 10. Block diagram of the control-mode 2 of the MI-DCPFC.

Similarly, we used the PI regulator tracking the correction current on line 2 and then comparing with the triangular carrier to obtain the drive pulse of the switch $S_{a}$. Also, we used the PI regulator tracking the correction current on line 3 and scaling it by the coefficient $k_{2}\left(k_{2}=T_{\mathrm{s}} / 2\right)$ to obtain the phase-shifted value. Finally, the phase-shifted pulse signal XORs with the pulse signal of $S_{a}$ can obtain the $\mathrm{T}_{3 \mathrm{~b}}$ drive pulse.

\subsection{Relationship of the System State Variable}

According to Figure 9, the timing chart diagram of the driving pulses under control-mode 1 can be obtained as Figure 11a. 


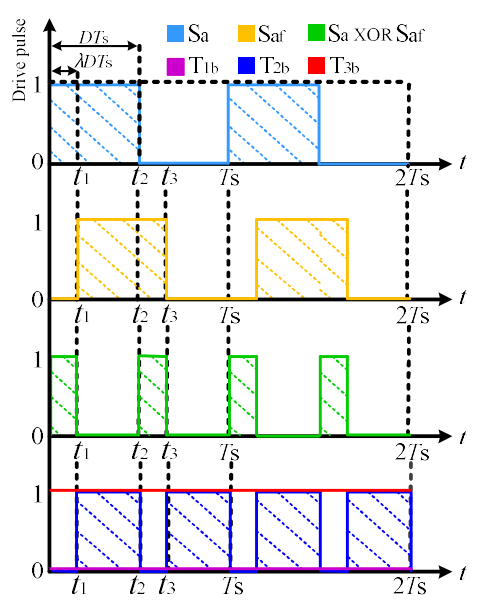

(a)

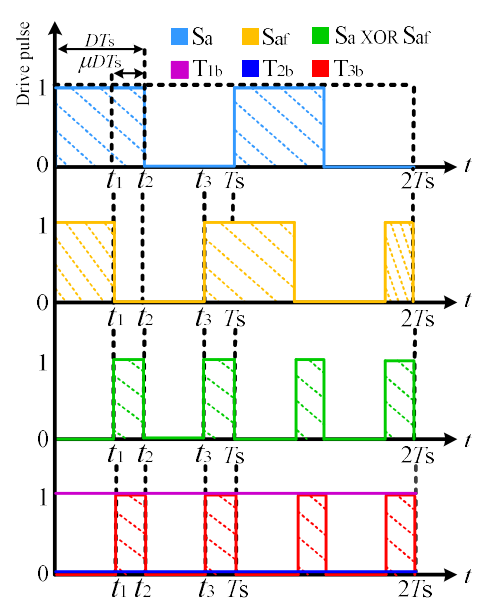

(b)

Figure 11. Timing chart diagram of the driving pulses: (a) timing chart diagram under control-mode 1;

(b) timing chart diagram under control-mode 2.

Assuming that the phase-shifted time is $t_{1}, T_{3 b}$ and $S_{a}$ will be in the on-state during $0-t_{1}$, which corresponds to the stage 3 of working-mode 1 . Further, the following equations can be established by combining Figure 7c:

$$
\begin{gathered}
V=-R_{1} i_{\mathrm{P} 1}-L_{1} \frac{\mathrm{d} i_{\mathrm{P} 1}}{\mathrm{~d} t}+V_{1} \\
V=-R_{2} i_{\mathrm{P} 2}-L_{2} \frac{\mathrm{d} i_{\mathrm{P} 2}}{\mathrm{~d} t}+V_{2} \\
V=-R_{3} i_{\mathrm{P} 3}-L_{3} \frac{\mathrm{d} i_{\mathrm{P} 3}}{\mathrm{~d} t}+u_{c}+V_{3} \\
i_{\mathrm{P} 3}=-C \frac{\mathrm{d} u_{c}}{\mathrm{~d} t}
\end{gathered}
$$

where $V$ is DC side voltage of the converter node to which the terminal $T$ is connected. $V_{1}, V_{2}$, and $V_{3}$ are the DC side voltages of the converter nodes to which the terminal $P_{1}, P_{2}$ and $P_{3}$ are connected, respectively. $R_{1}, R_{2}, R_{3}$ and $L_{1}, L_{2}, L_{3}$ are the equivalent resistance and inductance values of the transmission lines 1 to 3 , respectively. $i_{\mathrm{P} 1}, i_{\mathrm{P} 2}, i_{\mathrm{P} 3}$ are the instantaneous current of the transmission lines 1 to 3 , respectively. $u_{\mathrm{c}}$ is the capacitor voltage of the MI-DCPFC.

By defining $x^{\mathrm{T}}=\left[i_{\mathrm{P} 1}, i_{\mathrm{P} 2}, i_{\mathrm{P} 3}, u_{\mathrm{c}}\right]$ as the state variable of the system, the Equations (1)-(4) can be rewritten to a matrix form, as shown in Equation (5).

$$
\mathrm{Z} \times \frac{\mathrm{d}}{\mathrm{d} t}\left[\begin{array}{c}
i_{\mathrm{P} 1} \\
i_{\mathrm{P} 2} \\
i_{\mathrm{P} 3} \\
u_{c}
\end{array}\right]=\left[\begin{array}{cccc}
-R_{1} & 0 & 0 & 0 \\
0 & -R_{2} & 0 & 0 \\
0 & 0 & -R_{3} & 1 \\
0 & 0 & -1 & 0
\end{array}\right]\left[\begin{array}{c}
i_{\mathrm{P} 1} \\
i_{\mathrm{P} 2} \\
i_{\mathrm{P} 3} \\
u_{c}
\end{array}\right]+\mathrm{E} \times\left[\begin{array}{c}
V \\
V_{1} \\
V_{2} \\
V_{3}
\end{array}\right]
$$

where:

$$
Z=\left[\begin{array}{cccc}
L_{1} & 0 & 0 & 0 \\
0 & L_{2} & 0 & 0 \\
0 & 0 & L_{3} & 0 \\
0 & 0 & 0 & C
\end{array}\right], E=\left[\begin{array}{cccc}
-1 & 1 & 0 & 0 \\
-1 & 0 & 1 & 0 \\
-1 & 0 & 0 & 1 \\
0 & 0 & 0 & 0
\end{array}\right]
$$

Besides, it is easy to observe that the time periods $t_{1}-t_{2}, t_{2}-t_{3}$ and $t_{3}-T_{\mathrm{S}}$ in Figure 11a correspond to stage 2, stage 4 and stage 1 in the working-mode 1, respectively. Therefore, the system matrix equations in each time period can be written as Equations (7)-(9) in the same way, respectively. 


$$
\begin{aligned}
& \mathrm{Z} \times \frac{\mathrm{d}}{\mathrm{d} t}\left[\begin{array}{c}
i_{\mathrm{P} 1} \\
i_{\mathrm{P} 2} \\
i_{\mathrm{P} 3} \\
u_{c}
\end{array}\right]=\left[\begin{array}{cccc}
-R_{1} & 0 & 0 & 0 \\
0 & -R_{2} & 0 & 1 \\
0 & 0 & -R_{3} & 1 \\
0 & -1 & -1 & 0
\end{array}\right]\left[\begin{array}{c}
i_{\mathrm{P} 1} \\
i_{\mathrm{P} 2} \\
i_{\mathrm{P} 3} \\
u_{c}
\end{array}\right]+\mathrm{E} \times\left[\begin{array}{c}
V \\
V_{1} \\
V_{2} \\
V_{3}
\end{array}\right] \\
& \mathrm{Z} \times \frac{\mathrm{d}}{\mathrm{d} t}\left[\begin{array}{c}
i_{\mathrm{P} 1} \\
i_{\mathrm{P} 2} \\
i_{\mathrm{P} 3} \\
u_{c}
\end{array}\right]=\left[\begin{array}{cccc}
-R_{1} & 0 & 0 & -1 \\
0 & -R_{2} & 0 & -1 \\
0 & 0 & -R_{3} & 0 \\
1 & 1 & 0 & 0
\end{array}\right]\left[\begin{array}{c}
i_{\mathrm{P} 1} \\
i_{\mathrm{P} 2} \\
i_{\mathrm{P} 3} \\
u_{c}
\end{array}\right]+\mathrm{E} \times\left[\begin{array}{c}
V \\
V_{1} \\
V_{2} \\
V_{3}
\end{array}\right] \\
& \mathrm{Z} \times \frac{\mathrm{d}}{\mathrm{d} t}\left[\begin{array}{c}
i_{\mathrm{P} 1} \\
i_{\mathrm{P} 2} \\
i_{\mathrm{P} 3} \\
u_{c}
\end{array}\right]=\left[\begin{array}{cccc}
-R_{1} & 0 & 0 & -1 \\
0 & -R_{2} & 0 & 0 \\
0 & 0 & -R_{3} & 0 \\
1 & 0 & 0 & 0
\end{array}\right]\left[\begin{array}{c}
i_{\mathrm{P} 1} \\
i_{\mathrm{P} 2} \\
i_{\mathrm{P} 3} \\
u_{c}
\end{array}\right]+\mathrm{E} \times\left[\begin{array}{c}
V \\
V_{1} \\
V_{2} \\
V_{3}
\end{array}\right]
\end{aligned}
$$

In order to facilitate the subsequent analysis, the coefficient $\lambda$ is introduced to establish the quantitative relationship between the phase-shifted time $t_{1}$ and the duty ratio $D$ of $S_{a}$ drive pulse:

$$
\lambda=\frac{t_{1}}{D T_{\mathrm{s}}}
$$

Combining Equation (10) and Figure 11a, we further obtained:

$$
\begin{gathered}
\frac{t_{2}-t_{1}}{T_{\mathrm{s}}}=(1-\lambda) D \\
\frac{t_{3}-t_{2}}{T_{\mathrm{S}}}=\lambda D \\
\frac{T_{\mathrm{s}}-t_{3}}{T_{\mathrm{S}}}=1-(1+\lambda) D
\end{gathered}
$$

Concluding Equations (5)-(13), the system state equation of MI-DCPFC in one control period $\mathrm{T}_{\mathrm{s}}$ can be integrated as:

$$
\mathrm{Z} \times \frac{\mathrm{d}}{\mathrm{d} t}\left[\begin{array}{c}
i_{\mathrm{P} 1} \\
i_{\mathrm{P} 2} \\
i_{\mathrm{P} 3} \\
u_{c}
\end{array}\right]=\left[\begin{array}{cccc}
-R_{1} & 0 & 0 & -1+D \\
0 & -R_{2} & 0 & (1-2 \lambda) D \\
0 & 0 & -R_{3} & D \\
1-D & -(1-2 \lambda) D & -D & 0
\end{array}\right]\left[\begin{array}{c}
i_{\mathrm{P} 1} \\
i_{\mathrm{P} 2} \\
i_{\mathrm{P} 3} \\
u_{c}
\end{array}\right]+\mathrm{E} \times\left[\begin{array}{c}
V \\
V_{1} \\
V_{2} \\
V_{3}
\end{array}\right]
$$

When the system is operating stable, the change of the state variable can be ignored, and the Equation (14) can be further written as:

$$
\left[\begin{array}{cccc}
-R_{1} & 0 & 0 & -1+D \\
0 & -R_{2} & 0 & (1-2 \lambda) D \\
0 & 0 & -R_{3} & D \\
1-D & -(1-2 \lambda) D & -D & 0
\end{array}\right]\left[\begin{array}{c}
I_{\mathrm{P} 1} \\
I_{\mathrm{P} 2} \\
I_{\mathrm{P} 3} \\
U_{c}
\end{array}\right]+\mathrm{E} \times\left[\begin{array}{c}
V \\
V_{1} \\
V_{2} \\
V_{3}
\end{array}\right]=0
$$

Solving the matrix equation shown in Equation (15), we can obtain the average capacitor voltage expression of the MI-DCPFC as:

$$
U_{c}=\frac{(1-D)\left(V_{1}-V\right)-D R_{1}\left[\frac{(1-2 \lambda)\left(V_{2}-V\right)}{R_{2}}+\frac{\left(V_{3}-V\right)}{R_{3}}\right]}{(1-D)^{2}+D^{2} R_{1}\left[\frac{(1-2 \lambda)^{2}}{R_{2}}+\frac{1}{R_{3}}\right]}
$$


In the same way, we can obtain the timing chart diagram of the driving pulses under control-mode 2 firstly, as shown in Figure 11b. Then, the coefficient $\mu$ characterizing the phase-shifted time in this control-mode is introduced, where $\mu=\left(t_{2}-t_{1}\right) / D T_{\mathrm{s}}$. Finally, the average capacitor voltage expression of MI-DCPFC under this case can be obtained as:

$$
U_{c}=\frac{(1-D)\left(V_{2}-V\right)-D R_{2}\left[\frac{(1 / D-1-2 \mu)\left(V_{2}-V\right)}{R_{3}}+\frac{\left(V_{1}-V\right)}{R_{1}}\right]}{(1-D)^{2}+D^{2} R_{2}\left[\frac{(1 / D-1-2 \mu)^{2}}{R_{3}}+\frac{1}{R_{1}}\right]}
$$

Concluding Equations (16) and (17), it can be observed that when MI-DCPFC participates in the system power flow regulation, its capacitor voltage is related to the voltage drop and the rated parameters of the DC transmission line. This conclusion is also similar to the analysis results of the traditional CFC in reference [26]. In addition, it should be noted that as this type of MI-DCPFC cannot realize the reverse control of line current, the most extreme power regulation condition it faces is when all line currents are increased at the line with the largest line resistance. In other words, we can think that for the controlled lines, the capacitor voltage provided by DCPFC is the largest voltage under this condition. In this way, we can estimate the capacity design requirements of the MI-DCPFC, so as to ensure that it will not be damaged by the capacitor overvoltage when it is inserted into the system under normal operation. Furthermore, since this capacitor voltage is also the voltage level that the MI-DCPFC switches need to withstand, it can help to select the suitable switching devices.

\subsection{Control Method Extension of an Arbitrary Port MI-DCPFC}

In previous analysis, we take a three-port MI-DCPFC as the example, its basic working principle and implementation of control method are analyzed in detail. To make the results more general, we extend for an arbitrary port MI-DCPFC in this section.

Assuming that $n$ shunt lines are connected to the MI-DCPFC, and $m$ line currents need to control reduced, the other $n-m$ lines currents that need to be controlled increased. This result can follow the following main control principles during the implementation process:

(1) Selection of controlled lines: all lines that currents need to be reduced and $n-m+1$ lines that currents need to be increased are under an active-controlled state. In this way, by tracking the current regulation commands of $n-1$ branches, the overall control of $n$ line currents can be realized;

(2) Generation of $\mathrm{HB}_{0}$ drive pulse: to appropriately balance the carrier phase-shifted margin between both of the control-modes, the branch that he current reduced was centered among the $m$ branches can be selected as a reference, and then generated the drive pulse of $\mathrm{HB}_{0}$;

(3) Generation of $\mathrm{HB}_{\mathrm{i}}$ drive pulse: on this basis of step (2), the remaining $n-2$ active-controlled branches are tracking the current reduced and increased regulation commands through the control-mode 1 and -mode 2, respectively. Then generate the corresponding driving pulses of $\mathrm{HB}_{i}$, respectively. In addition, the upper and lower switches of the only one branch that remained are kept turned-off and turned-on, respectively.

According to the above ideas, it should be assumed that the branches 1 to $m$ are current reduced lines, and the branches $m+1$ to $n$ are current increased lines. Taking the forward current direction as the example, Figure 12 shows the overall control block diagram of the MI-DCPFC when the branch 1 is adopted as the reference branch. 


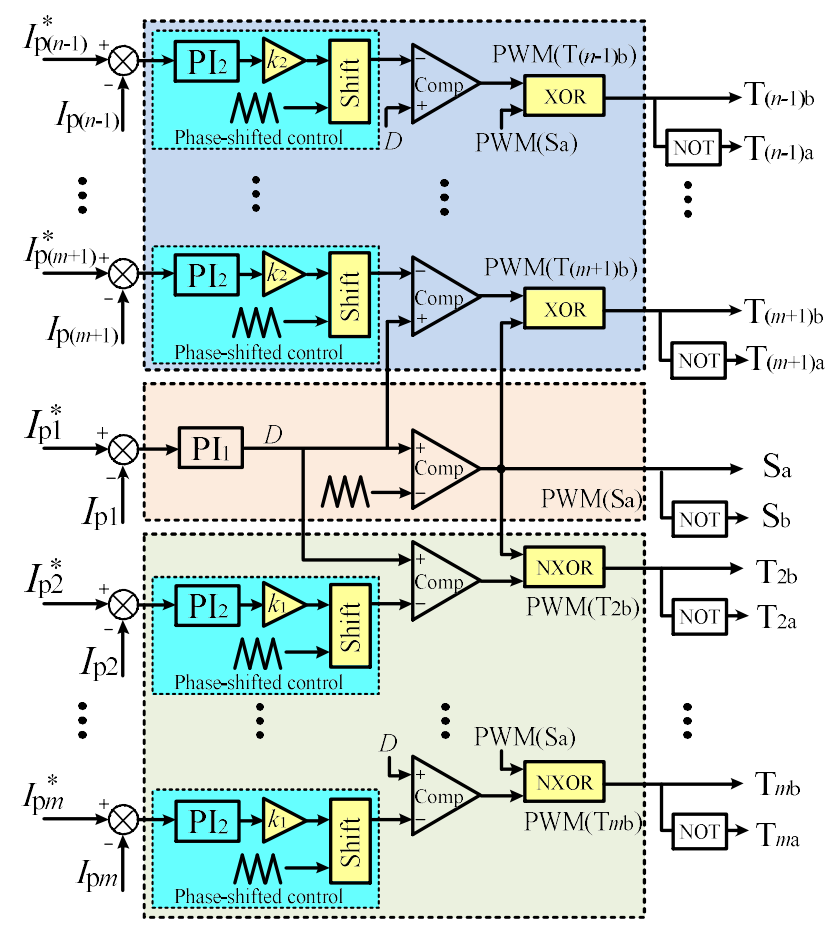

Figure 12. General control diagram of the arbitrary port MI-DCPFC.

\section{Simulation Results}

To confirm the proposed MI-DCPFC topology and control strategy, the related verification was carried out in MATLAB/SIMULINK. The five-terminal HVDC transmission system as shown in Figure 1 (repainting it as Figure 13a) and a more complicated five-terminal HVDC transmission system with four-port MI-DCPFC as shown in Figure 13b were developed, respectively.

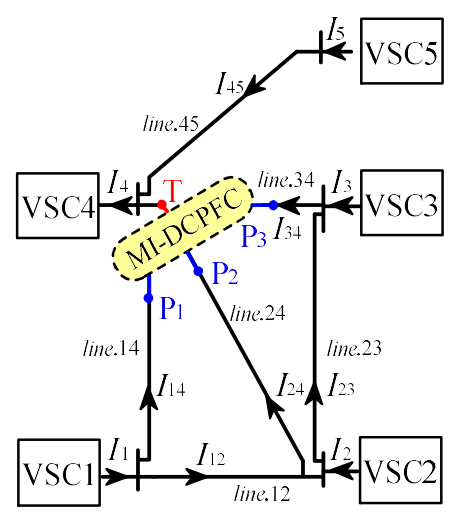

(a)

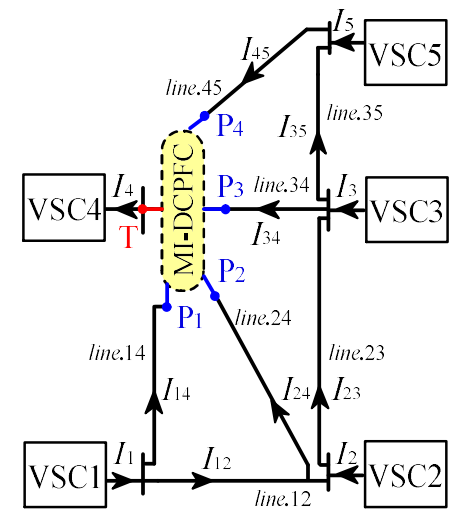

(b)

Figure 13. Schematic diagrams of the tested five-terminal DC transmission system: (a) topology with the three-port MI-DCPFC; (b) topology with the four-port MI-DCPFC.

The converter node VSC4 controls the systems DC bus voltage at $200 \mathrm{kV}$. The converter nodes VSC1 to VSC3 and the converter node VSC5 respectively inject P1 $=80 \mathrm{MW}, \mathrm{P} 2=100 \mathrm{MW}, \mathrm{P} 3=60 \mathrm{MW}$ and $\mathrm{P} 5=80 \mathrm{MW}$ active power into the system. The main parameters of each transmission line are shown in Table 4. 
Table 4. Line parameters of the five-terminal HVDC transmission systems.

\begin{tabular}{ccccc}
\hline Transmission Line & Length/km & Resitance/ $\boldsymbol{\Omega}$ & Inductance/mH & Capacitance/uF \\
\hline line.14 & 200 & 2.0 & 80 & 240 \\
line.24 & 100 & 1.0 & 40 & 120 \\
line.34 & 300 & 3.0 & 120 & 360 \\
line.45 & 150 & 1.5 & 60 & 180 \\
line.12 & 120 & 1.2 & 48 & 144 \\
line.23 & 100 & 1.0 & 40 & 120 \\
line.35 & 100 & 1.0 & 40 & 120 \\
\hline
\end{tabular}

\subsection{Three-Port MI-DCPFC Verified Results}

\subsubsection{Case 1}

The working-mode 1 ( $I_{14}$ is reduced; $I_{24}$ and $I_{34}$ are increased) was verified in this case. In addition, to make it easy to compare and analyze each one, the simplified MI-DCPFC with the traditional and novel control methods were both tested, respectively.

The performance of the MI-DCPFC with the traditional control method in this case is shown in Figure $14 \mathrm{a}-\mathrm{c}$. The MI-DCPFC is accessed into the system at $0.2 \mathrm{~s}$, and with the command controlling line. 14 current reduces to $I_{14}=0.1 \mathrm{kA}$. It can be seen that before adjusting the line currents, the system is operating at a stable rate, and the values of each line current are about $I_{14}=0.35 \mathrm{kA} ; I_{24}=0.62 \mathrm{kA}$; $I_{34}=0.23 \mathrm{kA} ; I_{45}=0.40 \mathrm{kA} ; I_{12}=0.06 \mathrm{kA} ; I_{23}=-0.07 \mathrm{kA}$, respectively. When the MI-DCPFC is inserted to the system at $0.2 \mathrm{~s}$, the controlled line current $I_{14}$ quickly respond to the command value and maintain stable operation, as shown in Figure 14a. In addition, as shown in Figure 14b,c, the voltage $V_{\mathrm{TP} 1}$ introduced in the line 14 is stably switched between 0 and $U_{\mathrm{c}}$; while the voltages introduced in line 24 and line 34 are synchronized to switch between 0 and $-U_{c}$, so $I_{24}$ and $I_{34}$ automatically respond to $I_{24}=0.82 \mathrm{kA}$ and $I_{34}=0.28 \mathrm{kA}$, respectively. We found that the specific increased amounts of the currents $I_{24}$ and $I_{34}$ cannot be controlled separately at this time, which is consistent with the theoretical analysis in the previous section.

The performance of the MI-DCPFC with the novel control method is shown in Figure 14d-g. The MI-DCPFC is inserted to the system at $0.2 \mathrm{~s}$, and with the command in control, $I_{14}$ reduces to $I_{14}=0.1 \mathrm{kA}$ and $I_{24}$ remains unchanged. When operating to $1.2 \mathrm{~s}$, the regulation command is re-changed, where with controlling $I_{14}$ reduced to $0.1 \mathrm{kA}$, but control $I_{24}$ increases to $0.7 \mathrm{kA}$. It can be observed that when the MI-DCPFC is accessed in the system, the controlled line current $I_{14}$ can also quickly respond to $I_{14}=0.1 \mathrm{kA}$ and maintain stable operation, as shown in Figure $14 \mathrm{~d}$. What is more, it can be found that unlike with the traditional control method, as the voltage $V_{\text {TP2 }}$ introduced in the line24 can be controlled and stably switched between $U_{\mathrm{c}}, 0$ and $-U_{\mathrm{c}}$, so the increased amounts of the current $I_{24}$ can be controlled freely at the same time.

The above simulation results show that the simplified MI-DCPFC with the novel control strategy can achieve the power flow control quickly and stably under the working-mode 1 . Furthermore, when compared to the traditional control strategy, on the basis of the reducing control of the line current, the increased value of other line currents can be also controlled freely at the same time. In addition, the capacitor voltage fluctuation is small, and the voltage state introduced in the connection line by the output port is consistent with the theoretical analysis. 

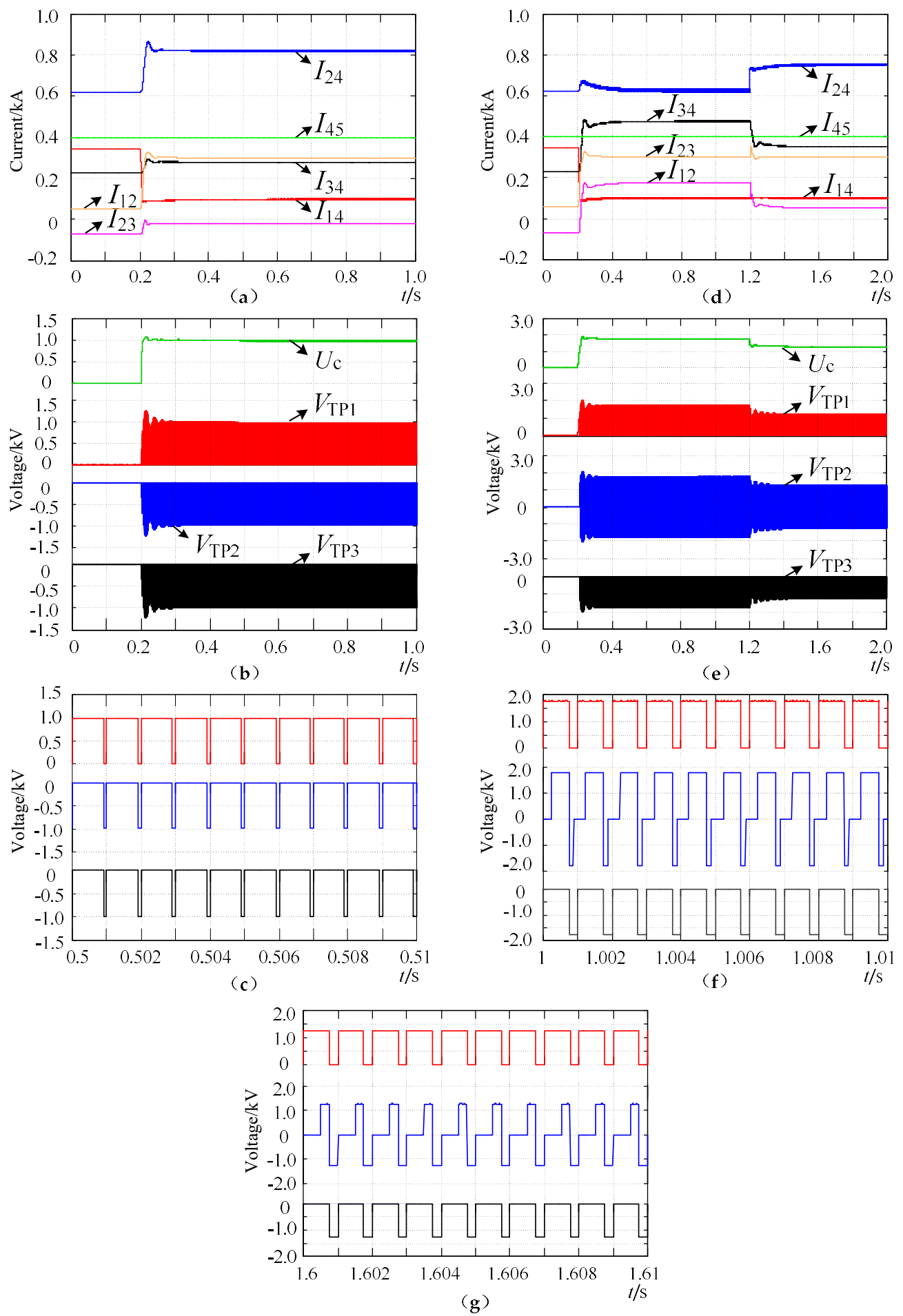

Figure 14. Simulation results of three-port MI-DCPFC under Case 1: (a) line currents with the traditional control method; (b) capacitor and port-output voltages with the traditional control method; (c) enlarged view of Figure $14 \mathrm{~b}$ among $0.5-0.51 \mathrm{~s}$; (d) line currents with the novel control method; (e) capacitor and port-output voltages with the novel control method; (f) enlarged view of Figure 14e among 1-1.01s; (g) enlarged view of Figure 14e among 1.6-1.61 s. 


\subsubsection{Case 2}

The working-mode 6 ( $I_{24}$ and $I_{34}$ are reduced; $I_{14}$ is increased) was verified in this case. Similarly, to make it easy to compare and analyze the simplified MI-DCPFC with the traditional and novel control methods were tested, respectively.

The performance of the MI-DCPFC with the traditional control method in this case is shown in Figure 15a-c. The MI-DCPFC is accessed into the system at $0.2 \mathrm{~s}$, and with the command controlling line 34 , the current reduces to $I_{34}=0.15 \mathrm{kA}$. It can be observed that the controlled line current $I_{34}$ quickly responds to the command value and maintains stable operation when the MI-DCPFC is accessed in the system at $0.2 \mathrm{~s}$, as shown in Figure 15a. However, as shown in Figure $15 \mathrm{~b}, \mathrm{c}$, since the voltage $V_{\text {TP2 }}$ introduced in the line 24 and voltage $V_{\text {TP } 3}$ introduced in line 34 are synchronized to switch between 0 and $U_{c}$, although the $I_{34}$ is also reduced, its specific reduced amounts cannot be controlled separately at this time.
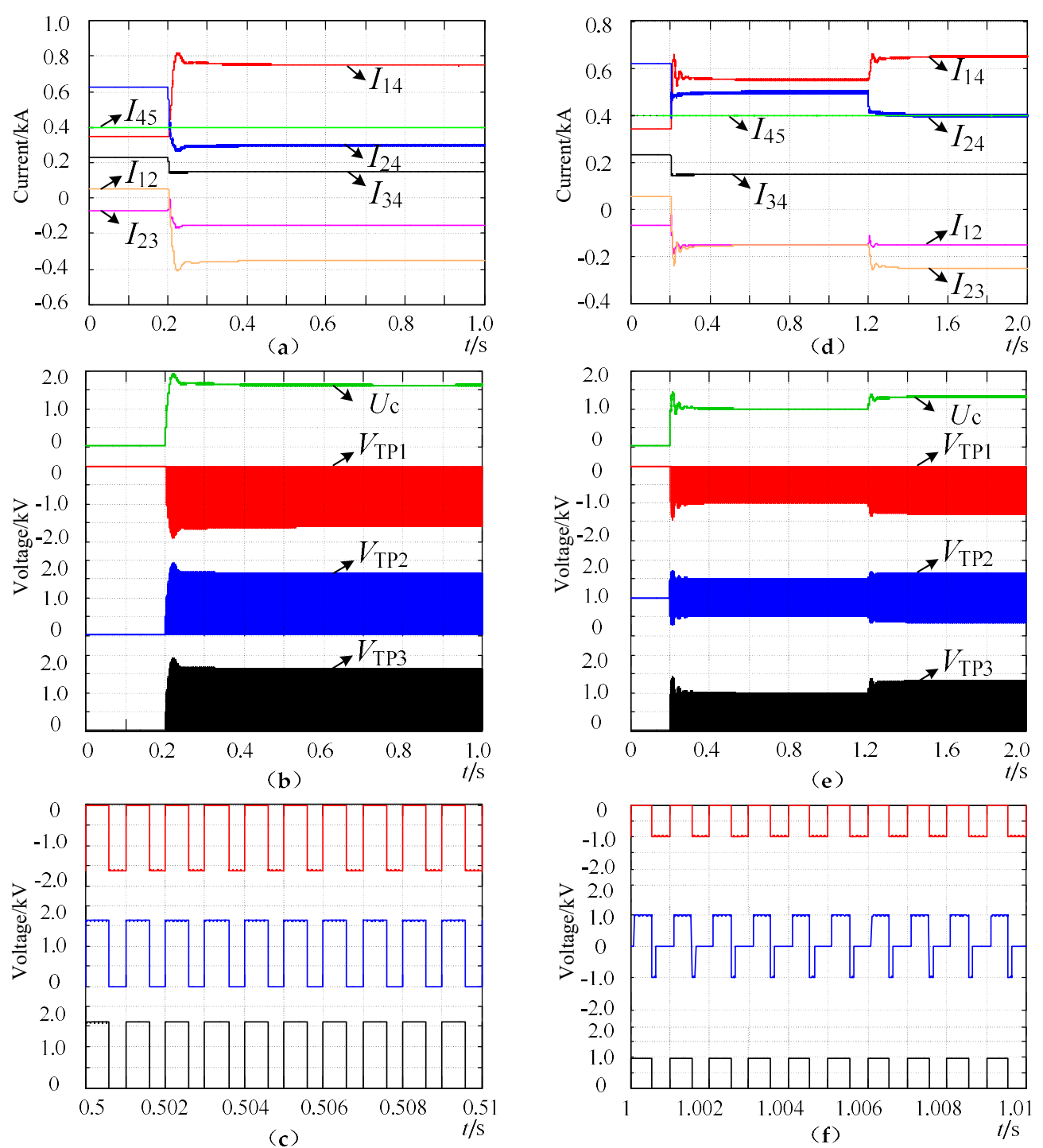

Figure 15. Cont. 


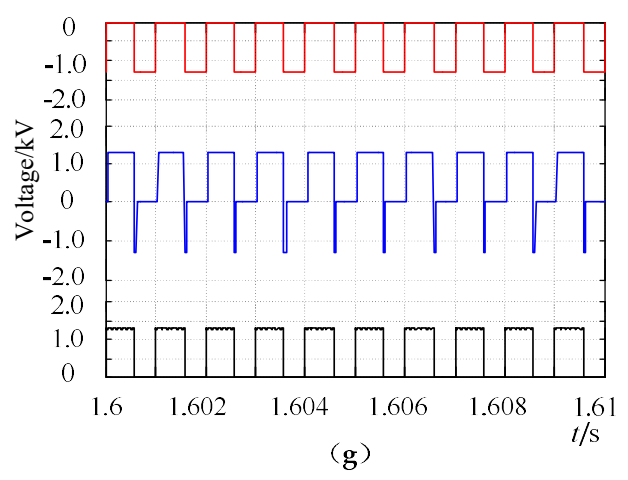

Figure 15. Simulation results of three-port MI-DCPFC under Case 2: (a) line currents with the traditional control method; (b) capacitor and port-output voltages with the traditional control method; (c) enlarged view of Figure 15b among 0.5-0.51 s; (d) line currents with the novel control method; (e) capacitor and port-output voltages with the novel control method; (f) enlarged view of Figure 15e among 1-1.01 s; (g) enlarged view of Figure 15e among 1.6-1.61 s.

The performance of the MI-DCPFC with the novel control method is shown in Figure 15d-g. The MI-DCPFC is accessed in the system at $0.2 \mathrm{~s}$, and with the command in control, $I_{24}$ and $I_{34}$ are reduced to $I_{24}=0.5 \mathrm{kA}$ and $I_{34}=0.15 \mathrm{kA}$, respectively. When operating to $t_{4}$, the power flow control command is re-changed, where with controlling occurring, $I_{34}$ was reduced to $0.15 \mathrm{kA}$, but control $I_{24}$ further reduces to $0.4 \mathrm{kA}$. It can be observed that when the MI-DCPFC is accessed in the system, the controlled line current $I_{34}$ quickly responded to $I_{34}=0.15 \mathrm{kA}$ and maintained stable operation, as shown in Figure $15 \mathrm{~d}$. What is more, the reduced amounts of the current $I_{24}$ can simultaneously be controlled freely with the reducing control of $I_{34}$. Correspondingly, the voltage $V_{\mathrm{TP} 2}$ introduced in the line 24 is controlled and stably switched between $U_{c}, 0$ and $-U_{c}$, as shown in Figure $15 \mathrm{e}-\mathrm{g}$.

The simulation results in this case show that the simplified MI-DCPFC with the novel control strategy can achieve the power flow regulation quickly and stably under the working-mode 6 . Furthermore, compared to the traditional control strategy, independent reduction control of each line current can be achieved when multiple line currents are reduced. Meanwhile, the capacitor voltage fluctuation is small, and the voltage state introduced in the connection line by the output port is consistent with the theoretical analysis.

\subsection{Four-Port MI-DCPFC Verified Results}

In order to further test the performance of the MI-DCPFC, the verification of a four-port MI-DCPFC was carried out. When the system starts up normally, it is tested with the following three different conditions, and the performance of the MI-DCPFC is shown in Figure 16; the measurement values of each line current under different test conditions are shown in Table 5.

(1) At $0.2 \mathrm{~s}$, control $I_{14}$ reduces to $0.05 \mathrm{kA}$, and control $I_{24}$ and $I_{45}$ increase to $0.7 \mathrm{kA}$ and $0.5 \mathrm{kA}$, respectively;

(2) At $0.2 \mathrm{~s}$, control $I_{14}$ and $I_{45}$ reduce to $0.2 \mathrm{kA}$ and $0.3 \mathrm{kA}$, respectively; and control $I_{24}$ increases to $0.7 \mathrm{kA}$;

(3) At $0.2 \mathrm{~s}$, control $I_{14}, I_{45}$ and $I_{24}$ reduce to $0.2 \mathrm{kA}, 0.3 \mathrm{kA}$ and $0.4 \mathrm{kA}$, respectively. 

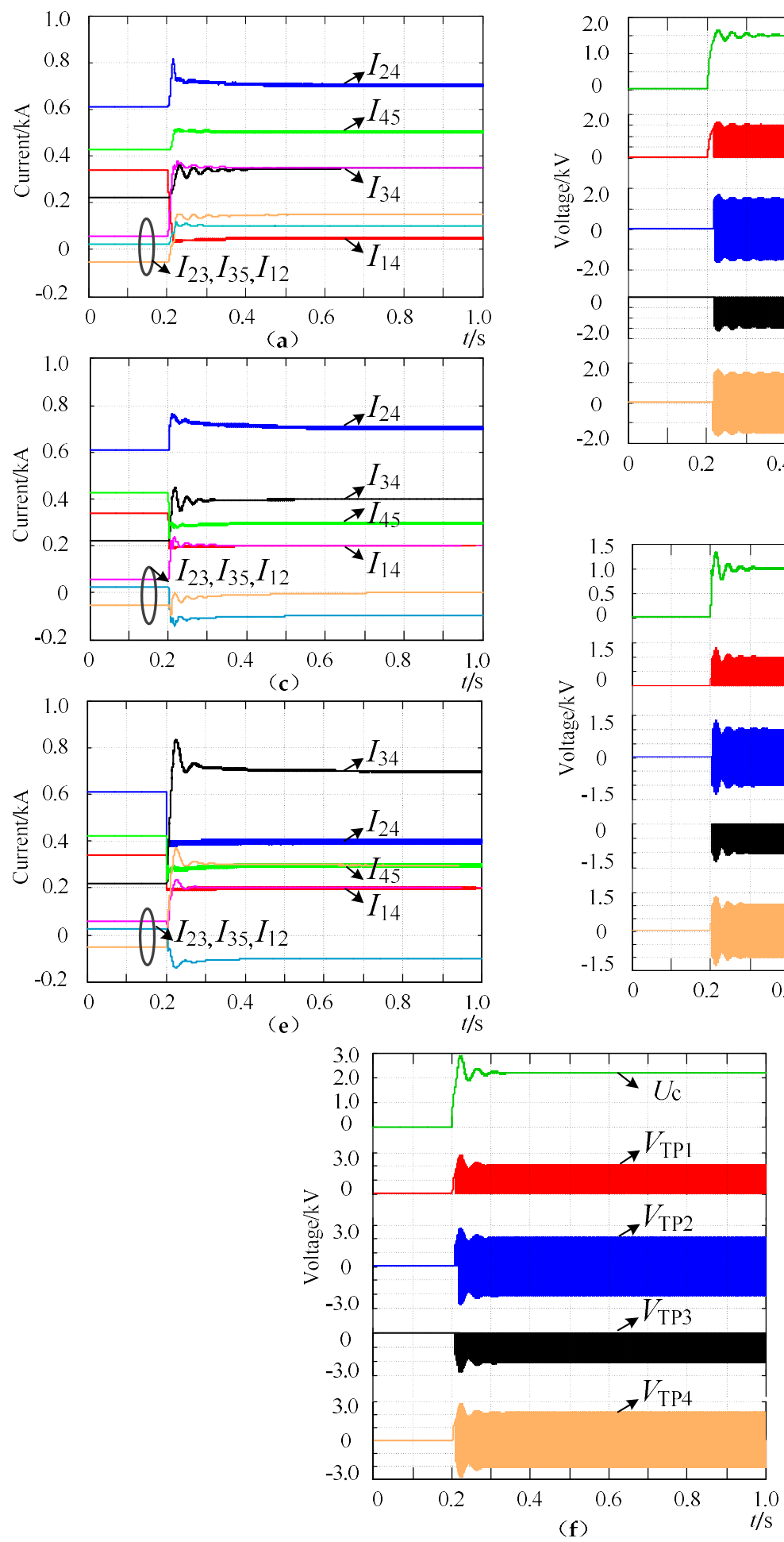

Figure 16. Simulation results of four-port MI-DCPFC: (a) line currents under condition 1; (b) capacitor and port-output voltages under condition $1 ;$ (c) line currents under condition 2; (d) capacitor and port-output voltages under condition 2; (e) line currents under condition 3 ; (f) capacitor and port-output voltages under condition 3.
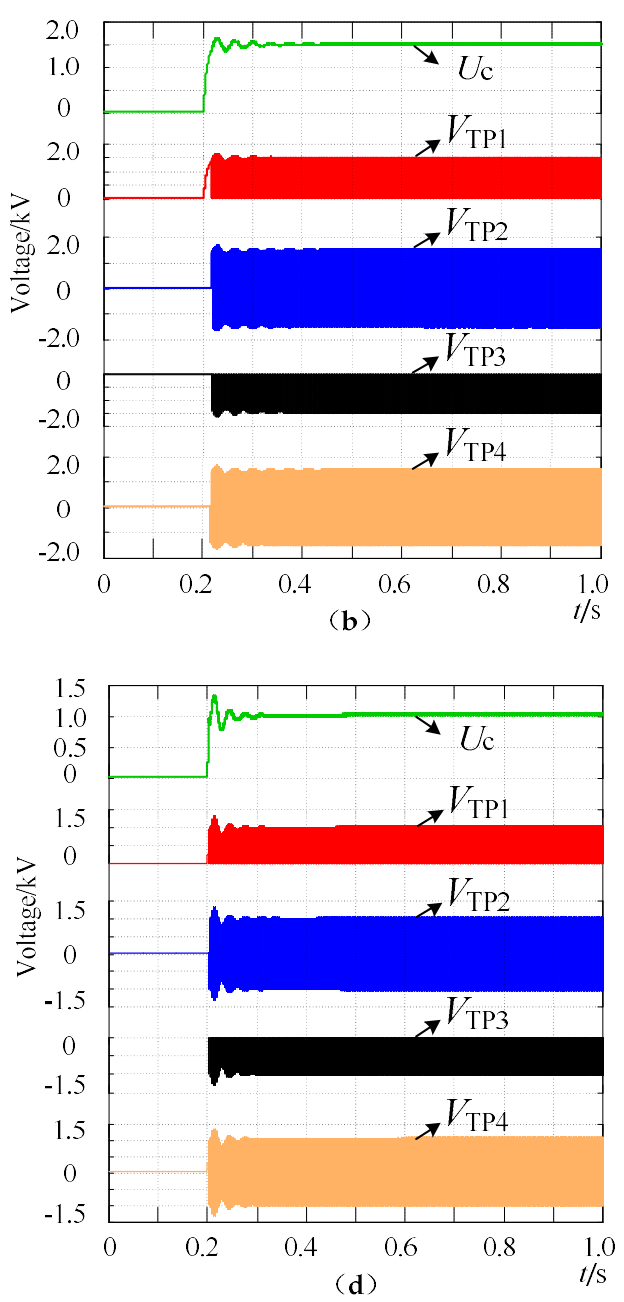

(d) 
Table 5. The measurement values of each line current under different test conditions.

\begin{tabular}{ccccc}
\hline Line Current/kA & No Command/kA & Condition $\mathbf{1 / k A}$ & Condition 2/kA & Condition 3/kA \\
\hline$I_{14}$ & 0.33 & 0.05 & 0.20 & 0.20 \\
$I_{45}$ & 0.43 & 0.50 & 0.30 & 0.30 \\
$I_{24}$ & 0.62 & 0.70 & 0.70 & 0.40 \\
$I_{34}$ & 0.21 & 0.35 & 0.40 & 0.70 \\
$I_{23}$ & -0.06 & 0.15 & 0 & 0.30 \\
$I_{12}$ & 0.07 & 0.35 & 0.20 & 0.20 \\
$I_{35}$ & 0.03 & 0.10 & -0.10 & -0.10 \\
\hline
\end{tabular}

It can be observed that under the different control conditions, the controlled lines can all quickly track the corresponding power flow control commands, and then maintain stable operation. In addition, we can note that in the test conditions 1 and 3, MI-DCPFC only operates in control-mode 1 and control-mode 2, respectively; in test condition 2, control-mode 1 and -mode 2 participate in the regulation work simultaneously.

Concluding all previous simulation studies in this section, it can be seen that with the CPS-PWM control strategy proposed in this paper, the simplified MI-DCPFC can achieve effective power flow control under different power flow regulation requirements and its response speed is faster.

\section{Experiments}

To verify the proposed MI-DCPFC topology and control strategy, the five-terminal HVDC transmission system consistent with the simulation was built in the laboratory. Figure 17 shows the photograph of the platform. Each module in the Units 1 to 3 has half-bridge and full-bridge as two different topology modes that could be selected. Different MI-DCPFC topologies can be formed by an appropriate selection and combination, as shown in Table 6. VSC1-VSC5 adopts a ITECH programmable digital power IT series, where VSC4 controls the systems DC bus voltage at $80 \mathrm{~V}$; VSC1 to 3 and VSC5 respectively inject $I_{1}=8 \mathrm{~A}, I_{2}=10 \mathrm{~A}, I_{3}=6 \mathrm{~A}$ and $I_{5}=8 \mathrm{~A}$ into the system. The transmission line parameters are shown in Table 7 . In addition, in order to facilitate the comparison and verification of the simulation results, the verified cases in the experiment are the same as for the simulation.

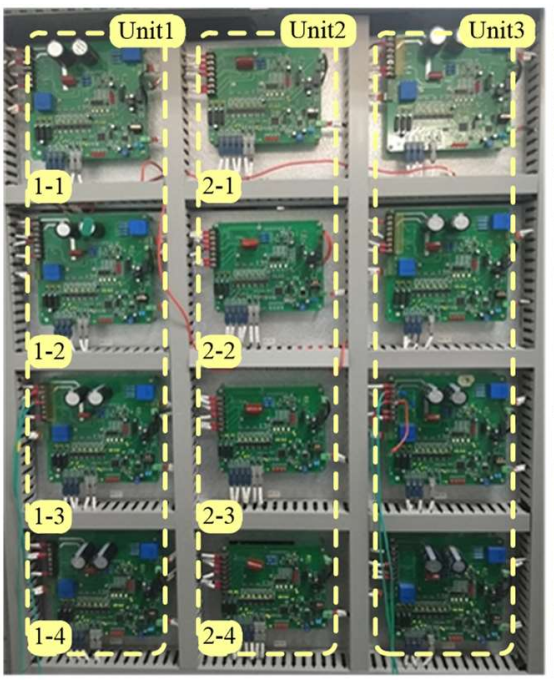

(a)

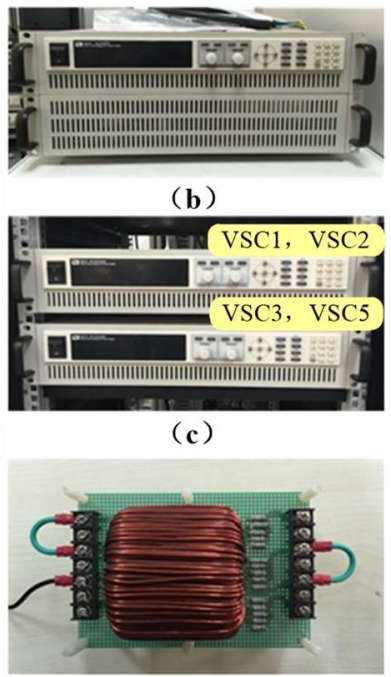

(d)

Figure 17. Photograph of the MI-DCPFC platform: (a) MI-DCPFC prototype; (b) VSC4; (c) VSC1-3 and 5; (d) line impedance module. 
Table 6. Implementation of the MI-DCPFC topology in the experiment.

\begin{tabular}{ccc}
\hline Topology & Selected Module Topology & Used Modules \\
\hline Traditional three-port MI-DCPFC & Full-bridge & $1-1 ; 2-1$ to -2 \\
Proposed three-port MI-DCPFC & Half-bridge & $1-1 ; 2-1$ to -3 \\
Proposed four-port MI-DCPFC & Half-bridge & $1-1 ; 2-1$ to -4 \\
\hline
\end{tabular}

Table 7. Line parameters in the experiment.

\begin{tabular}{ccc}
\hline Transmission Line & Resitance/ $\boldsymbol{\Omega}$ & Inductance $/ \mathbf{m H}$ \\
\hline line.14 & 2.0 & 4.0 \\
line.24 & 1.0 & 3.0 \\
line.34 & 3.0 & 5.0 \\
line.45 & 1.5 & 4.0 \\
line.12 & 1.2 & 3.0 \\
line.23 & 1.0 & 3.0 \\
line.35 & 1.0 & 3.0 \\
\hline
\end{tabular}

\subsection{Three-Port MI-DCPFC Verified Results}

\subsubsection{System Test}

With the topology of the transmission system shown in Figure 13a, Figure 18 shows the line currents of the transmission system with no MI-DCPFC accessed under the normal operation. It can be observed that the system operates in a stable manner when it starts up. The measured values of each line current are about $I_{14}=7 \mathrm{~A} ; I_{24}=12.8 \mathrm{~A} ; I_{34}=4.8 \mathrm{~A} ; I_{45}=4 \mathrm{~A} ; I_{12}=1.2 \mathrm{~A} ; I_{23}=-1.4 \mathrm{~A}$, respectively.
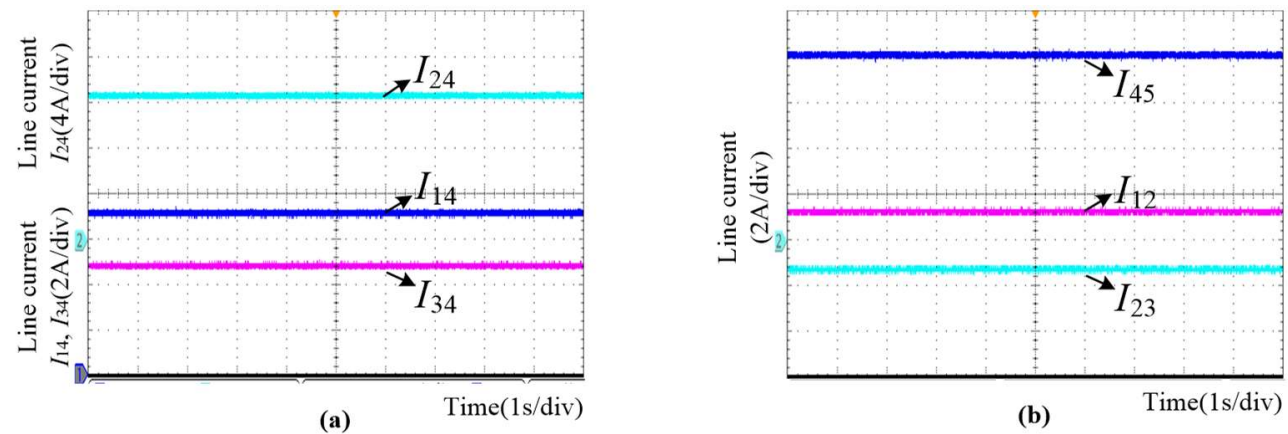

(b)

Figure 18. Experiment results under normal operation: (a) line currents part 1; (b) line currents part 2.

\subsubsection{Case 1}

The working-mode 1 ( $I_{14}$ is reduced; $I_{24}$ and $I_{34}$ are increased) was confirmed in this case. The performance of the MI-DCPFC with the traditional control method in this case is shown in Figure 19a-c. The MI-DCPFC is accessed into the system at $t_{1}$, and with the command controlling $I_{14}$ reduces to $I_{14}=2 \mathrm{~A}$. It can be seen that before adjusting the line currents, the system is operating in a stable manner. When the MI-DCPFC is inserted to the system at $t_{1}$, the controlled line current $I_{14}$ quickly responded to the command value and maintained stable operation, as shown in Figure 19a. In addition, as shown in Figure $19 \mathrm{~b}, \mathrm{c}$, the voltage $V_{\text {TP1 }}$ introduced in line 14 stably switched between 0 and $U_{\mathrm{c}}$; the voltages introduced in line 24 and line 34 were synchronized to switch between 0 and $-U_{\mathrm{c}}$, so $I_{24}$ and $I_{34}$ automatically responded to $I_{24}=16.8 \mathrm{~A}$ and $I_{34}=6 \mathrm{~A}$ respectively, where the specific increased amounts of the currents $I_{24}$ and $I_{34}$ cannot be controlled separately at this time. 

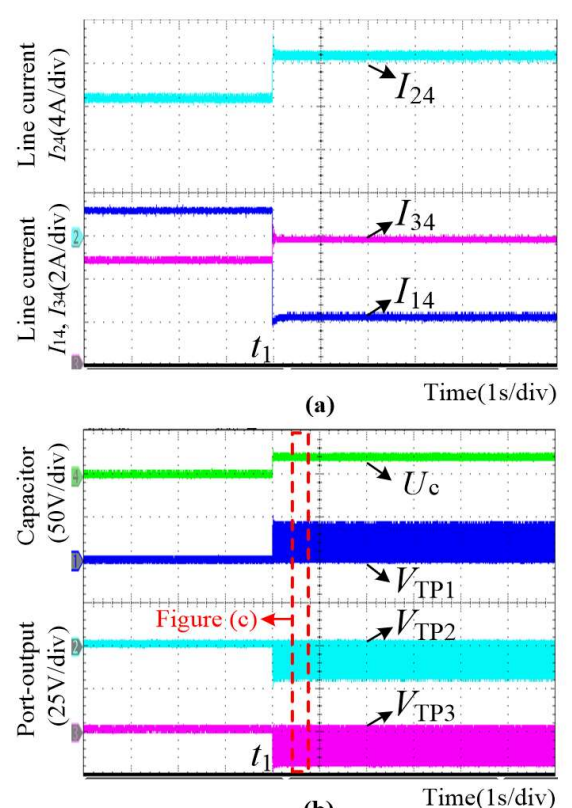

(b)

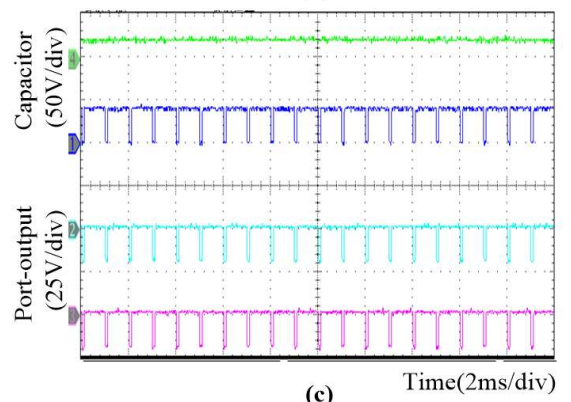

(c)

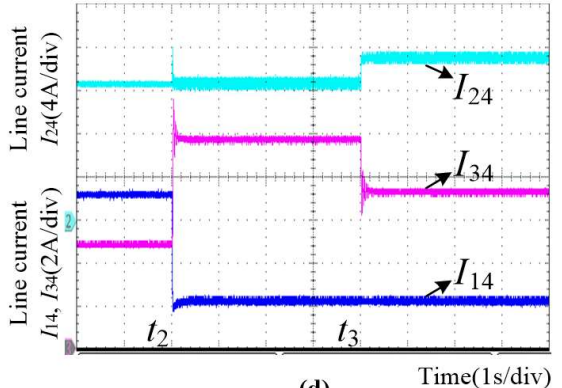

(d)

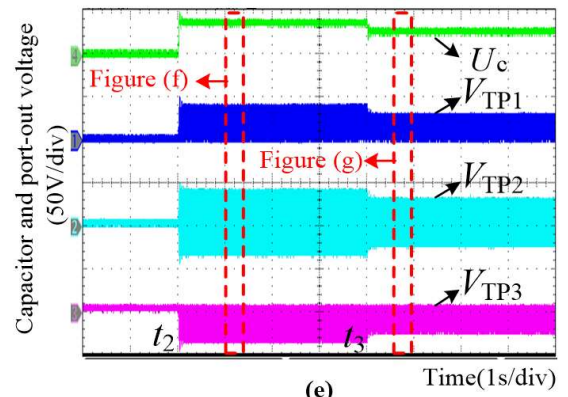

(e)

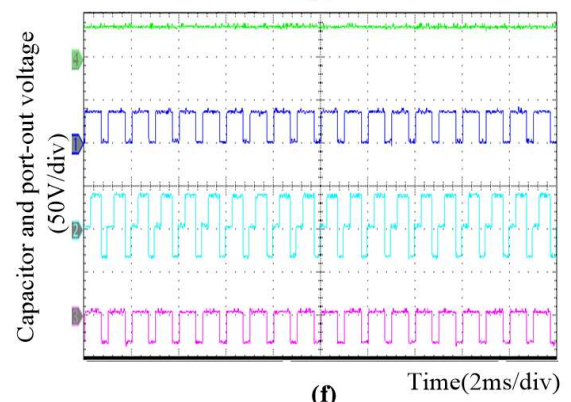

(f)

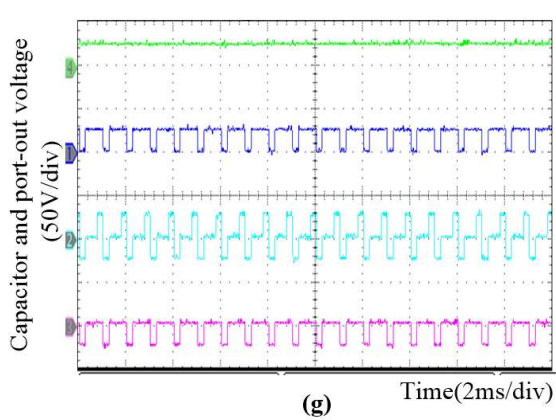

Figure 19. Experiment results of three-port MI-DCPFC under Case 1: (a) line currents with the traditional control method; (b) capacitor and port-output voltages with the traditional control method; (c) enlarged view of Figure 19b; (d) line currents with the novel control method; (e) capacitor and port-output voltages with the novel control method; (f) enlarged view 1 of Figure 19e; (g) enlarged view 2 of Figure 19e.

The performance of the MI-DCPFC with the novel control method is shown in Figure 19d-g. The MI-DCPFC is inserted to the system at $t_{2}$, and with the command in control, $I_{14}$ reduces to $I_{14}=2 \mathrm{~A}$ and $I_{24}$ remains unchanged. When operating to $t_{3}$, the regulation command is re-changed, where with controlling $I_{14}$ reduced to $2 \mathrm{~A}$, but control increased $I_{24}$ to $15 \mathrm{~A}$. It can be observed that when the MI-DCPFC is accessed into the system, the controlled line current $I_{14}$ also quickly responded to $2 \mathrm{~A}$ and maintained stable operation, as shown in Figure 19d. What is more, unlike with the traditional control method, since the voltage $V_{\text {TP2 }}$ introduced in line 24 can be controlled stably switched between $U_{\mathrm{c}}, 0$ and $-U_{\mathrm{c}}$, the increased amounts of the current $I_{24}$ can also be controlled freely at the same time. 


\subsubsection{Case 2}

The working-mode 6 ( $I_{24}$ and $I_{34}$ are reduced; $I_{14}$ is increased) was confirmed in this case. The performance of the MI-DCPFC with the traditional control method in this case is shown in Figure 20a-c. The MI-DCPFC is accessed into the system at $t_{4}$, and with the command controlling $I_{34}$ reduces to $I_{34}=3 \mathrm{~A}$.

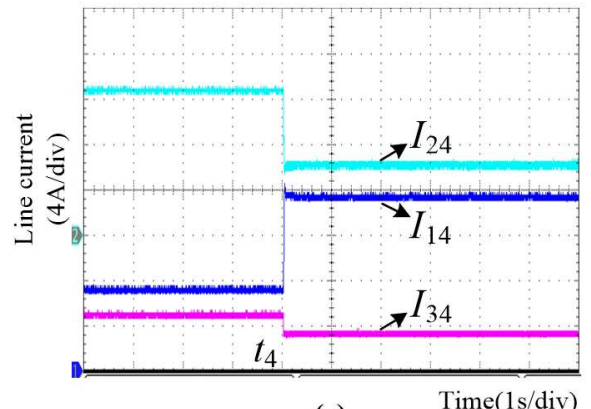

(a) $\operatorname{Time}(1 \mathrm{~s} / \mathrm{div})$

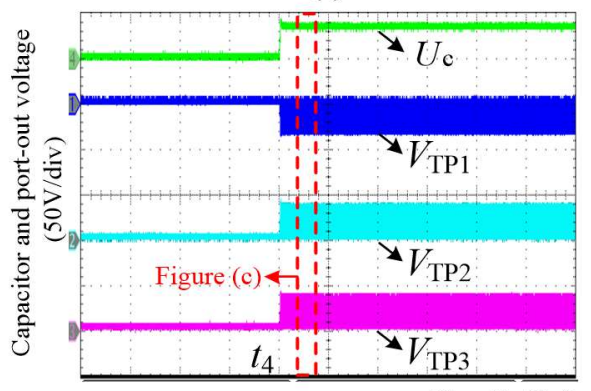

(b)

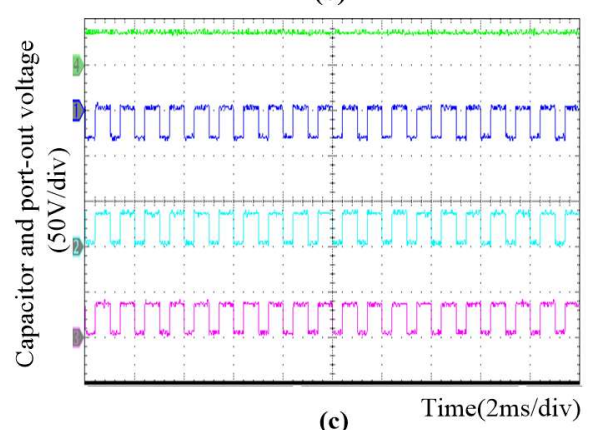

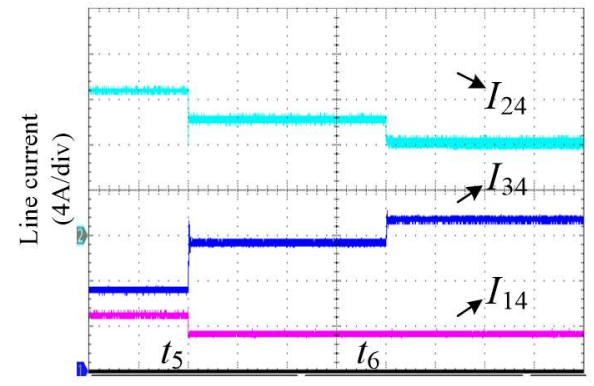

(d)

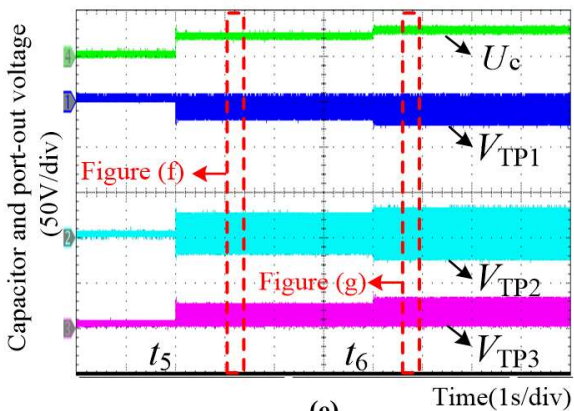

(e)

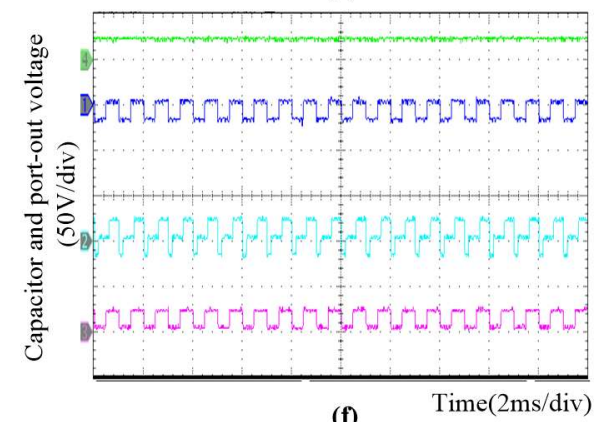

(f)

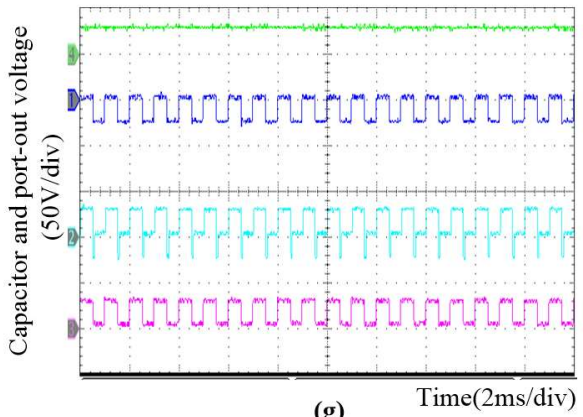

(g)

Figure 20. Experiment results of three-port MI-DCPFC under Case 2: (a) line currents with the traditional control method; (b) capacitor and port-output voltages with the traditional control method; (c) enlarged view of Figure 20a; (d) line currents with the novel control method; (e) capacitor and port-output voltages with the novel control method; (f) enlarged view 1 of Figure 20e; (g) enlarged view 2 of Figure 20e. 
It can be observed that the controlled line current $I_{34}$ quickly responded to the command value when the MI-DCPFC was inserted to the system at $t_{4}$, as shown in Figure 20a. However, as shown in Figure 20b,c, as the voltage $V_{\mathrm{TP} 2}$ introduced in line 24 and voltage $V_{\mathrm{TP} 3}$ introduced in line 34 were synchronized to switch between 0 and $U_{c}$, although the $I_{34}$ is also reduced, its specific reduced amounts could not be controlled separately at this time.

The performance of the MI-DCPFC with the novel control method is shown in Figure 20d-g. The MI-DCPFC is accessed into the system at $t_{5}$, and with the command controlling $I_{24}$ and $I_{34}$ are reduced to $I_{24}=3 \mathrm{~A}$ and $I_{34}=10 \mathrm{~A}$, respectively. When operating to $t_{6}$, the power flow control command is changed again, where with controlling, $I_{34}$ reduced to $3 \mathrm{~A}$, but control further reduces $I_{24}$ to $8 \mathrm{~A}$. It can be observed that when the MI-DCPFC is accessed into the system, the controlled line current $I_{34}$ also quickly responded to $3 \mathrm{~A}$, as shown in Figure 20d. What is more, the reduced amounts of the current $I_{24}$ can simultaneously be controlled freely with the reducing control of $I_{34}$. Correspondingly, the voltage $V_{\mathrm{TP} 2}$ introduced in line 24 is controlled and stably switched between $U_{\mathrm{c}}$, 0 and $-U_{\mathrm{c}}$, as shown in Figure 20e-g.

\subsection{Four-Port MI-DCPFC Verified Results}

\subsubsection{System Test}

With the topology of the transmission system shown in Figure 13b, Figure 21 shows the line currents of the transmission system with no MI-DCPFC accessed under the normal operation. It can be observed that the system operates stable when it starts up. The measured values of each line current are about $I_{14}=6.8 \mathrm{~A} ; I_{24}=12.5 \mathrm{~A} ; I_{34}=4.8 \mathrm{~A} ; I_{45}=8.6 \mathrm{~A} ; I_{12}=1.2 \mathrm{~A} ; I_{23}=-1.2 \mathrm{~A} ; I_{35}=0.6 \mathrm{~A}$, respectively.

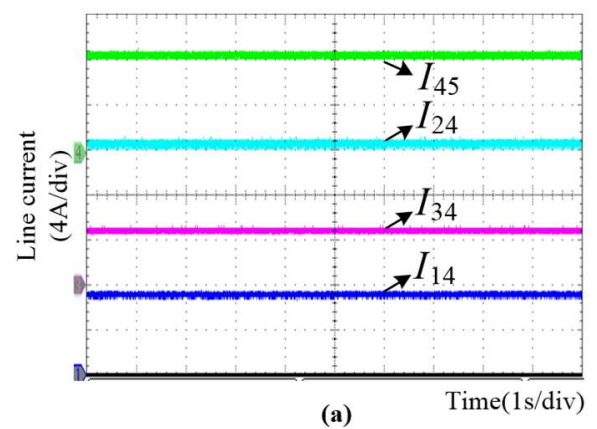

(a)

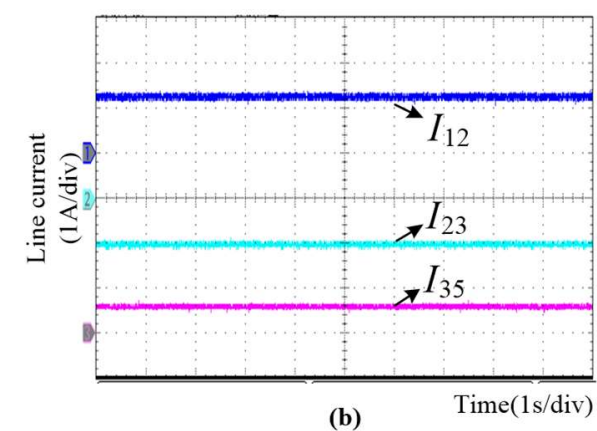

(b)

Figure 21. Experiment results under normal operation: (a) line currents part 1; (b) line currents part 2.

\subsubsection{Case Studies}

The four-port MI-DCPFC is confirmed in this section. Same as the simulation, the following three different cases are respectively confirmed when the system starts up normally.

(1) At $t_{1}$, control $I_{14}$ reduces to $1 \mathrm{~A}$, and control $I_{24}$ and $I_{45}$ increase to $14 \mathrm{~A}$ and $10 \mathrm{~A}$, respectively;

(2) At $t_{2}$, control $I_{14}$ and $I_{45}$ reduce to $4 \mathrm{~A}$ and $6 \mathrm{~A}$, respectively; and control $I_{24}$ increases to $14 \mathrm{~A}$;

(3) At $t_{3}$, control $I_{14}, I_{45}$ and $I_{24}$ reduce to $4 \mathrm{~A}, 6 \mathrm{~A}$ and $8 \mathrm{~A}$, respectively.

The main experiment results are shown in Figure 22; the measurement values of each line current under different test conditions are shown in Table 8. It can be observed that under the different control conditions, the controlled lines can all quickly track the corresponding power flow control commands, and then maintain stable operation. In addition, the capacitor voltage fluctuation is small, and the voltage state introduced in the connection line by the output port is stable. 


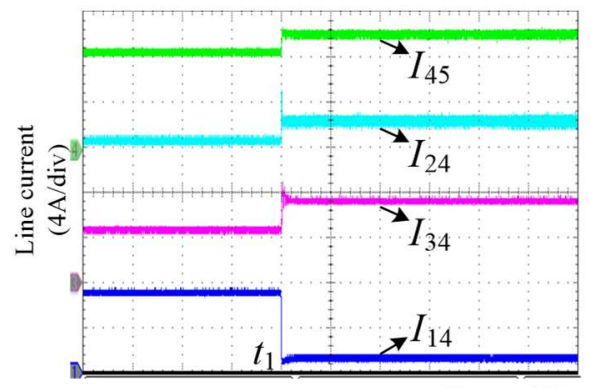

(a)

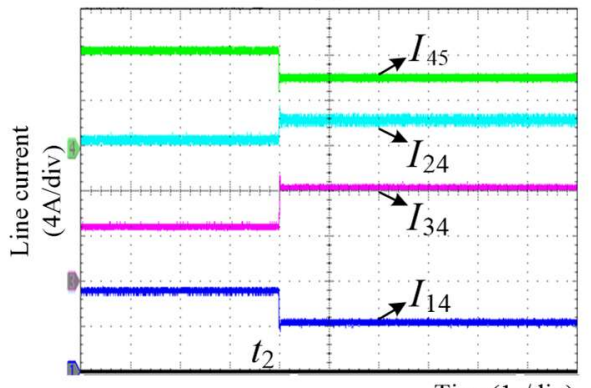

(b)

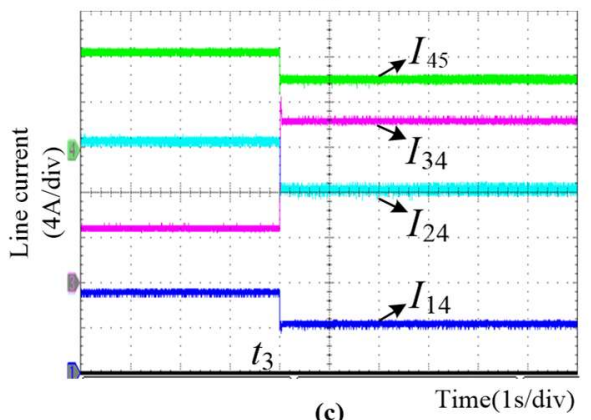

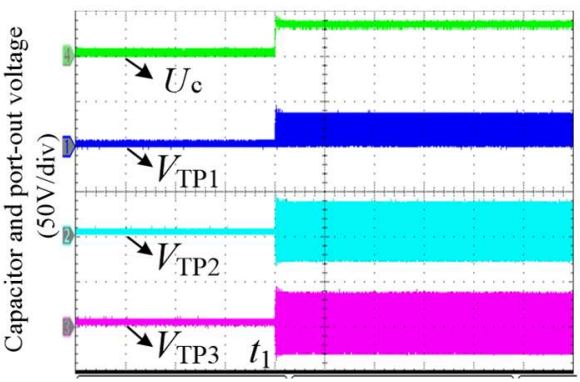

(d)

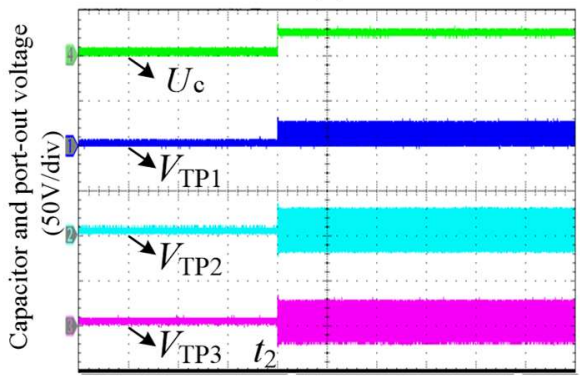

(e)

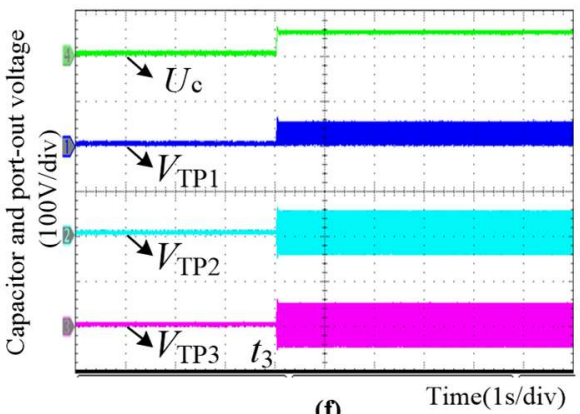

(f)

Figure 22. Experiment results of four-port MI-DCPFC: (a) line currents under case 1 ; (b) capacitor and port-output voltages under case 1 ; (c) line currents under case 2; (d) capacitor and port-output voltages under case 2; (e) line currents under case 3; (f) capacitor and port-output voltages under case 3.

Table 8. The measurement values of each line current under different test conditions in the experiment.

\begin{tabular}{ccccc}
\hline Line Current/kA & No Command /A & Case 1/A & Case 2/A & Case 3/A \\
\hline$I_{14}$ & 6.8 & 1 & 4 & 4 \\
$I_{45}$ & 8.6 & 10 & 6 & 6 \\
$I_{24}$ & 12.5 & 14 & 14 & 8 \\
$I_{34}$ & 4.8 & 7 & 8 & 14 \\
$I_{23}$ & -1.2 & 3 & 0 & 6 \\
$I_{12}$ & 1.2 & 7 & 4 & 4 \\
$I_{35}$ & 0.6 & 2 & -2 & -2 \\
\hline
\end{tabular}

Concluding all previous experiment studies in this section, it can be seen that the performances of the MI-DCPFC under different conditions are consistent with the results in the simulation. This shows that the simplified MI-DCPFC can achieve effective power flow control under different power flow regulation requirements.

\section{Conclusions}

The dc power flow control issue in multi-terminal HVDC transmission system was investigated in this paper. The main works and contributions can be summarized as: 
(1) Under the background of a interline dc power flow controller, the topology and operation principles of the traditional MI-DCPFC were analyzed. The analysis revealed that the upper and lower switches of the left half-bridge of the MI-DCPFC are always pulsed synchronously during the operating process, respectively. Based on this, this paper presents a switches reduced topology of MI-DCPFC.

(2) To solve the problem of coupling of the port-output voltage of the MI-DCPFC, a novel general control strategy based on CPS-PWM was proposed in this paper. It can help with realizing the decoupling of the port-output voltage of MI-DCPFC, which ensures completely independent tracking of the power flow regulating commands for different controlled transmission lines. In addition, key relationships between the system state variables were derived and analyzed in this study, and the relevant expression of the capacitor voltage of MI-DCPFC under steady state was obtained.

(3) Two five-terminal HVDC transmission systems were developed in the MATLAB/SIMULINK environment and experiment platform. Taking the three-port and four-port topology as examples, the performance of the power flow controller and related control strategy were verified under various test conditions. The results show that the transmission system with proposed MI-DCPFC can operate in a stable manner, and the controller can quickly and efficiently track the power flow regulation commands.

(4) The simplified topology and capacitor voltage decoupling control strategy of the traditional MI-DCPFC were studied in this paper. However, the question of how to further improve the controller and realize the self-control of the capacitor voltage and the line current reversal is the next research area to investigate.

Author Contributions: W.W. conceived and designed the study. X.W., L.J. and J.Y. given suggestions and revised the manuscript.

Funding: This research work is supported by the China Southern Power Grid Co., Ltd. Science and Technology Project: Research and Application of Key Technologies of Integrated Energy System Based on DC (090000KK52180116)

Conflicts of Interest: The authors declare no conflict of interest.

\section{Appendix A}

Table A1. Conduction states of the traditional three-port MI-DCPFC.

\begin{tabular}{cccccccccc}
\hline \multirow{2}{*}{ Mode } & Direction & Reduced & Increased & \multicolumn{5}{c}{ Switching States } \\
\cline { 6 - 9 } & & & & $\mathrm{S}_{\mathrm{c} 1}$ & $\mathrm{~S}_{\mathrm{c} 2}$ & $\mathrm{~S}_{\mathrm{c} 3}$ & $\mathrm{~S}_{\mathrm{d} 1}$ & $\mathrm{~S}_{\mathrm{d} 2}$ & $\mathrm{~S}_{\mathrm{d} 3}$ \\
\hline 1 & forward & $I_{\mathrm{p} 1}$ & $I_{\mathrm{p} 2}$ and $I_{\mathrm{p} 3}$ & & & & off & on & on \\
2 & forward & $I_{\mathrm{p} 2}$ & $I_{\mathrm{p} 1}$ and $I_{\mathrm{p} 3}$ & & & & on & off & on \\
3 & forward & $I_{\mathrm{p} 3}$ & $I_{\mathrm{p} 1}$ and $I_{\mathrm{p} 2}$ & & off & & on & on & off \\
4 & forward & $I_{\mathrm{p} 1}$ and $I_{\mathrm{p} 2}$ & $I_{\mathrm{p} 3}$ & & & & off & off & on \\
5 & forward & $I_{\mathrm{p} 1}$ and $I_{\mathrm{p} 3}$ & $I_{\mathrm{p} 2}$ & & & & off & on & off \\
6 & forward & $I_{\mathrm{p} 2}$ and $I_{\mathrm{p} 3}$ & $I_{\mathrm{p} 1}$ & & & & on & off & off \\
7 & reverse & $I_{\mathrm{p} 1}$ & $I_{\mathrm{p} 2}$ and $I_{\mathrm{p} 3}$ & on & off & off & & & \\
8 & reverse & $I_{\mathrm{p} 2}$ & $I_{\mathrm{p} 1}$ and $I_{\mathrm{p} 3}$ & off & on & off & & & \\
9 & reverse & $I_{\mathrm{p} 3}$ & $I_{\mathrm{p} 1}$ and $I_{\mathrm{p} 2}$ & off & off & on & & off & \\
10 & reverse & $I_{\mathrm{p} 1}$ and $I_{\mathrm{p} 2}$ & $I_{\mathrm{p} 3}$ & on & on & off & & & \\
11 & reverse & $I_{\mathrm{p} 1}$ and $I_{\mathrm{p} 3}$ & $I_{\mathrm{p} 2}$ & on & off & on & & & \\
12 & reverse & $I_{\mathrm{p} 2}$ and $I_{\mathrm{p} 3}$ & $I_{\mathrm{p} 1}$ & off & on & on & & & \\
\hline
\end{tabular}

\section{References}

1. Li, J.; Konstantinou, G.; Wickramasinghe, H.R.; Pou, J.; Wu, X.; Jin, X. Impact of Circulating Current Control in Capacitor Voltage Ripples of Modular Multilevel Converters Under Grid Imbalances. IEEE Trans. Power Deliv. 2018, 33, 1257-1267. [CrossRef] 
2. Lan, T.K.; Li, Y.H.; Duan, X.Z.; Zhu, J. Simplified Analytic Approach of Pole-to-Pole Faults in MMC-HVDC for AC System Backup Protection Setting Calculation. Energies 2018, 11, 264. [CrossRef]

3. Chen, W.; Zhu, X.; Yao, L. An Interline DC Power-Flow Controller (IDCPFC) for Multiterminal HVDC System. IEEE Trans. Power Deliv. 2015, 30, 2027-2036. [CrossRef]

4. Mu, Q.; Liang, J.; Li, Y.; Zhou, X. Power flow control devices in dc grids. In Proceedings of the 2012 IEEE Power and Energy Society General Meeting, San Diego, CA, USA, 22-26 July 2012; pp. 1-7.

5. Jovcic, D.; Ooi, B. Developing de transmission networks using de transformers. IEEE Trans. Power Deliv. 2010, 25, 2535-2543. [CrossRef]

6. Jovcic, D.; Lin, W. Multiport high-power LCL dc hub for use in dc transmission grids. IEEE Trans. Power Deliv. 2014, 29, 760-768. [CrossRef]

7. Natori, K.; Obara, H.; Yoshikawa, K.; Hiu, B.; Sato, Y. Flexible power flow control for next-generation multi-terminal DC power network. In Proceedings of the IEEE Energy Conversion Congress and Exposition (ECCE), Pittsburgh, PA, USA, 14-18 September 2014; pp. 778-784.

8. Barker, C.D.; Davidson, C.C.; Trainer, D.R. Requirements of DC-DC Converters to Facilitate Large DC Grids; CIGRE Session: Paris, France, 2012; pp. 1-10.

9. Kenzelmann, S.; Rufer, A.; Dujic, D. High frequency operation of a DC/AC/DC system for HVDC applications. IEEE Trans. Power Electron. 2015, 29, 4017-4115.

10. Luth, T.; Merlin, M.M.C.; Green, T.C. Isolated DC/DC structure based on modular multilevel converter. IEEE Trans. Power Electron. 2013, 30, 89-98.

11. Veilleux, E.; Ooi, B. Multi-terminal HVDC with thyristor power-flow controller. IEEE Trans. Power Deliv. 2012, 27, 1205-1212. [CrossRef]

12. Kim, S.; Cui, S.; Sul, S. Modular multilevel converter based on full bridge cells for multi-terminal DC transmission. In Proceedings of the European Conference on Power Electronics and Applications, Lappeenranta, Finland, 26-28 August 2014; pp. 1-10.

13. Balasubramaniam, S.; Liang, J.; Ugalde-Loo, C. An IGBT based series power flow controller for multi-terminal HVDC transmission. In Proceedings of the International Universities Power Engineering Conference (UPEC), Cluj-Napoca, Romania, 2-5 September 2014; pp. 1-6.

14. Zhang, T.; Li, C.; Liang, J. A thyristor based series power flow control device for multi-terminal HVDC transmission. In Proceedings of the International Universities Power Engineering Conference (UPEC), Cluj-Napoca, Romania, 2-5 September 2014; pp. 1-5.

15. Subhasish, M.; Tomas, J.; Sasitharan, S. An Apparatus for Controlling the Electric Power Transmission in a HVDC Power Transmission System. PCT WO 2012/037966 A1, 2012.

16. Barker, C.; Whitehouse, R. A current flow controller for use in HVDC grids. In Proceedings of the IET International Conference on AC and DC Power Transmission (ACDC), Birmingham, UK, 4-5 December 2012; pp. 1-5.

17. Deng, N.; Wang, P.; Zhang, X. A DC Current Flow Controller for Meshed Modular Multilevel Converter Multiterminal HVDC Grids. CSEE J. Power Energy Syst. 2015, 1, 43-51. [CrossRef]

18. Diab, H.Y.; Marei, M.I.; Tennakoon, S.B. Reduced Switch Count Topology of Current Flow Control Apparatus for MTDC Grids. J. Power Electron. 2016, 16, 1743-1751. [CrossRef]

19. Sau-Bassols, J.; Prieto-Araujo, E.; Gomis-Bellmunt, O. Modeling and control of an interline current flow controller for meshed HVDC grids. IEEE Trans. Power Deliv. 2017, 32, 11-22. [CrossRef]

20. Sau-Bassols, J.; Prieto-Araujo, E.; Gomis-Bellmunt, O. Series Interline DC/DC Current Flow Controller for Meshed HVDC Grids. IEEE Trans. Power Deliv. 2018, 33, 881-891. [CrossRef]

21. Cao, Y.; Yao, L.; Yang, B. A novel DC power flow controller for VSC-MTDC system. In Proceedings of the International Conference on Renewable Power Generation (RPG 2015), Beijing, China, 17-18 October 2015; pp. 1-6.

22. Ning, G.; Chen, W.; Zhu, X. A Novel Interline DC Power-Flow Controller (IDCPFC) for Meshed HVDC Grids. In Proceedings of the Energy Conversion \& Congress \& Exposition, Milwaukee, WI, USA, 18-22 September 2016; pp. 1-7.

23. Chen, W.; Zhu, X.; Yao, L. A Novel Interline DC Power-Flow Controller (IDCPFC) for Meshed HVDC Grids. IEEE Trans. Power Deliv. 2016, 31, 1719-1727. [CrossRef] 
24. Ranjram, M.; Lehn, P.W. A three-port power flow controller for HVDC grids. In Proceedings of the International Conference on Power Electronics and ECCE Asia (ICPE-ECCE Asia), Seoul, Korea, 1-5 June 2015; pp. 1-5.

25. Ranjram, M.; Lehn, P.W. A multiport power-flow controller for DC transmission grids. IEEE Trans. Power Deliv. 2016, 31, 389-396. [CrossRef]

26. Diab, H.Y.; Marei, M.I.; Tennakoon, S.B. Operation and control of an insulated gate bipolar transistor-based current controlling device for power flow applications in multi-terminal high-voltage direct current grids. IET Power Electron. 2016, 9, 305-315. [CrossRef]

(C) 2019 by the authors. Licensee MDPI, Basel, Switzerland. This article is an open access article distributed under the terms and conditions of the Creative Commons Attribution (CC BY) license (http://creativecommons.org/licenses/by/4.0/). 